\title{
ORIGINAL ARTICLE Neural progenitor fate decision defects, cortical hypoplasia and behavioral impairment in Celsr1-deficient mice
}

\author{
C Boucherie ${ }^{1}$, C Boutin ${ }^{1,5}$, Y Jossin ${ }^{2}$, O Schakman ${ }^{3}$, AM Goffinet ${ }^{1}$, L Ris $^{4}$, P Gailly ${ }^{3}$ and F Tissir ${ }^{1}$
}

The development of the cerebral cortex is a tightly regulated process that relies on exquisitely coordinated actions of intrinsic and extrinsic cues. Here, we show that the communication between forebrain meninges and apical neural progenitor cells (aNPC) is essential to cortical development, and that the basal compartment of aNPC is key to this communication process. We found that Celsr1, a cadherin of the adhesion G protein coupled receptor family, controls branching of aNPC basal processes abutting the meninges and thereby regulates retinoic acid (RA)-dependent neurogenesis. Loss-of-function of Celsr1 results in a decreased number of endfeet, modifies RA-dependent transcriptional activity and biases aNPC commitment toward self-renewal at the expense of basal progenitor and neuron production. The mutant cortex has a reduced number of neurons, and Celsr 1 mutant mice exhibit microcephaly and behavioral abnormalities. Our results uncover an important role for Celsr1 protein and for the basal compartment of neural progenitor cells in fate decision during the development of the cerebral cortex.

Molecular Psychiatry (2018) 23, 723-734; doi:10.1038/mp.2017.236; published online 19 December 2017

\section{INTRODUCTION}

The cerebral cortex is the seat of higher brain functions and its formation requires the production and positioning of a right number and diversity of neurons for intricate circuits assembly. During early cortical development, neural stem cells (NSC) divide symmetrically in the ventricular zone (VZ) and both daughter cells re-enter the cell cycle, leading to an increased number of NSC. At the onset of neurogenesis, radial or apical (aNPC), the progenitors of excitatory cortical neurons, which derive from NSC, shift from a symmetric/proliferative to an asymmetric/differentiative mode of division. Asymmetric divisions produce aNPC as well as neurons, either directly or indirectly through basal/intermediate progenitors (BP). ${ }^{1}$ Each BP divides symmetrically to give rise to postmitotic neurons, thus increasing the final output of neurons. ${ }^{1,2}$ Hence, a delicate balance between the proliferation and differentiation of aNPC must be maintained during neurogenesis. This balance is regulated by intrinsic and extrinsic factors at the level of individual aNPC, which undergo a rigorous sequence of fate choices. Errors in fate decisions often lead to devastating disorders that vary from severe and lethal malformations, to cognitive, social and motor disabilities. ${ }^{3}$

The Celsr 1 gene codes for an atypical cadherin usually located at epithelial cells adherens junctions where it coordinates polarity in the plane of the epithelium, in cooperation with a set of conserved 'core' planar cell polarity (PCP) genes/proteins such as Vangl2 or Fzd3 and 6. ${ }^{4}$ Mice carrying mutations in Celsr1 have defects in neural tube closure, ${ }^{5-7}$ inner ear hair cells, ${ }^{6}$ cilia polarity, ${ }^{8,9}$ as well as in cell movement and rearrangement. ${ }^{10,11}$ In humans, mutations of CELSR 1 are associated with craniorachischisis, ${ }^{12}$ the most severe form of neural tube closure defects. Despite the robust and maintained expression of Celsr 1 in the developing forebrain germinal zones, ${ }^{13}$ its function, after neural tube closure, has not been assessed.

Here, we report that at the onset of neurogenesis, the Celsr1 protein localizes to the endfeet of aNPC and has an important role in shaping their basal compartment. Compared with those of control mice, Celsr1-deficient aNPC endfeet have fewer contact with the basal lamina and are less accessible to retinoic acid (RA) delivered by meningeal cells. They undergo more proliferative divisions, thereby expanding the pool of aNPC at the expense of $\mathrm{BP}$ and neuron production, and leading to marked morphological and behavioral defects. Finally, we provide evidence that RA signaling controls fate decision of neural progenitors.

\section{MATERIALS AND METHODS}

Mutant mice and in vivo treatment

All procedures were carried out in accordance with European guidelines and approved by the animal ethics committee of the Universite catholique de Louvain. Mouse lines used in this study are: Celsri ${ }^{-/-}$and Celsr ${ }^{f / f}, 7$ Nestin-CreERT (C57BL/6-Tg(Nes-cre/ERT2)KEisc/J; Jackson Lab, Bar Harbor, ME, USA), Rosa-dTomato (B6.CgGt(ROSA)26Sortm9(CAG-dTomato)Hze/J; Jackson Lab), D/x5/6-Cre-IRES-eGFP ( $T g(m / 56 i-c r e, E G F P) 1 \mathrm{Kc} /$; ; Jackson Lab) and Emx1-Cre (B6.Cg-Emxtm1(cre)Krj/J; Jackson Lab). For in utero RA supplementation, pregnant females were subjected to a daily intraperitoneal injection of $20 \mathrm{mg} \mathrm{kg}^{-1}$ of RA. Cell fate experiments in Celsr ${ }^{-1-}$; Nestin-CreERT ${ }^{2}$; lox-STOP-lox dTomato mice were carried out at e14.5 after a single 4-Hydroxytamoxifen injection $(1.25 \mathrm{mg})$ in pregnant female at e13.5. Clonal analyses in Celsr $7^{\mathrm{f} / \mathrm{f}}$;Nestin-CreERT ${ }^{2}$;lox-STOP-lox dTomato embryos were performed at e14.5 after a single 4-Hydroxytamoxifen injection at e10.5 (0.3 mg per pregnant female).

\footnotetext{
${ }^{1}$ Université catholique de Louvain, Institute of Neuroscience, Developmental Neurobiology, Brussels, Belgium; ${ }^{2}$ Université catholique de Louvain, Institute of Neuroscience, Mammalian Development and Cell Biology, Brussels, Belgium; ${ }^{3}$ Université catholique de Louvain, Institute of Neuroscience, Cell Physiology, Brussels, Belgium and ${ }^{4}$ Neuroscience

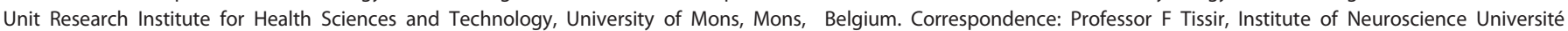
catholique de Louvain, Avenue Mounier, 73, Box B1.73.16, Brussels 1200, Belgium.

E-mail: fadel.tissir@uclouvain.be

${ }^{5}$ Present address: Institut de Biologie du Développement, Marseille, France.

Received 24 May 2016; revised 21 July 2017; accepted 17 August 2017; published online 19 December 2017
} 


\section{Behavioral tests}

All the mice were tested at 3 months of age. The open-field test was used to assess a non-forced ambulation as mice can move freely without any influence of the examiner. Mice were placed in a square arena $(60 \times 60 \mathrm{~cm})$ and video tracked (Ethovision 6.1, Noldus; Wageningen, The Netherlands) for $20 \mathrm{~min}$. The total distance covered by animals and the time spent in the center versus periphery were measured.

The elevated plus maze test was used to assess anxiety. Mice were placed in an elevated plus maze consisting of two opposing open arm (exposed place) and two opposing closed arm (safer place). Time spent in each arm and distance covered were recorded by a video tracking system for 5 min.

Morris water maze was used to assess spatial learning and memory. Water maze was made of a round pool with a diameter of $113 \mathrm{~cm}$ virtually divided into four quadrants (North, South, West and East) and filled with water $(26 \mathrm{C})$. Several visual cues were placed around the pool. Mice were tested during 4 days with three consecutive trials per day. During the trials, animals were placed in the pool facing the sidewall and allowed to swim freely to the platform visible the first day and submerged $1 \mathrm{~cm}$ under the water surface for the 3 next days. The platform was placed at the center of the North-East quadrant of the pool and maintained in this position throughout the 4 days. The initial position in which the animal was left in the pool varied among trials. If the animal did not find the platform during a period of $60 \mathrm{~s}$, it was gently guided to it. Then, it was allowed to remain on the platform for $5 \mathrm{~s}$ and removed from the pool before being placed in the next initial starting position in the pool. On the 5th day, the animals were submitted to a probe test that consisted in allowing the animals to swim freely for $1 \mathrm{~min}$ in the pool without the escape platform. During the trial and the probe test, mice were video-tracked. The time latency to reach the platform, the swim speed, and the time spent in each quadrant were measured.

The three-chamber test was used to assess sociability. The test box was divided into three equal compartments $(20 \mathrm{~cm}$ each), and dividing walls had retractable doorways allowing access into each chamber. First, for habituation, test mice were placed in the middle chamber for $5 \mathrm{~min}$ with the doorways closed. Then, to evaluate sociability, the test mice were placed in the central compartment and an unfamiliar mouse, called stranger, was restricted in a wire cage placed in one of the side compartments, whereas the other side compartment contains an empty wire cage. The test mice were video tracked for $10 \mathrm{~min}$. The total distance covered by the animals and the time spent in each chamber were measured.

\section{Immunohistochemistry}

We used $12 \mu \mathrm{m}$-thick cryosections from embryos, fixed $30-45 \mathrm{~min}$ in $4 \%$ paraformaldehyde and $50 \mu \mathrm{m}$-thick slices (sliding microtome) from postnatal brains fixed with $4 \%$ paraformaldehyde. Sections were blocked in PBS supplemented with $0.5 \%$ Triton X-100 and 3\% Bovine serum albumin, and incubated with the following primary antibodies: Celsr1 (homemade, 1/500), Laminin (Sigma-Aldrich, Overijse, Belgium, Cat no. L9393, 1/50), Nestin (Chemicon/Millipore, Overijse, Belgium, Cat no. MAB353, 1/1000), Pax6 (Covance, Cat no. MAB353, 1/500), Tbr2 (Abcam, Brussels, Belgium, Cat no. ab23345, 1/500), Tuj1 (Covance, Cat no. MMS-435P-0250, 1/500), Crabp2 (Abcam, Cat no. ab74365, 1/100), Sox2 (Millipore, Cat no. AB5603, 1/500), Mash1 (BD Pharmigen, Erembodegem, Belgium, Cat no. 556604, 1/200), phospho-Vimentin (Abcam, Cambdrige, UK, Cat no. ab22651, 1/100), Satb2 (Abcam, Cat no. ab51502, 1/1000), Cux1 (Santa Cruz, Santa Cruz, CA, USA, at no. SC-13024, 1/500), Foxp2 (Abcam, Cat no. ab16046, 1/1000) and Ctip2 (Abcam, Cat no. ab18465, 1/500).

Whole-mount preparation of the ventricular wall

Lateral ventricular walls were dissected and immediately immersed in PBS as described previously. ${ }^{8}$ Whole-mount preparations were fixed in $4 \%$ paraformaldehyde and $0.1 \%$ Triton X-100 for $12 \mathrm{~min}$, washed three times in PBS- $0.1 \%$ Triton X-100, blocked in PBS supplemented with $0.5 \%$ Triton $\mathrm{X}-100$ and $3 \%$ BSA, and incubated with $\beta$-Catenin antibody (Cell Signaling, Danvers, MA, USA, Cat no. 9581, 1/500), ZO-1 (Invitrogen, Brussels, Belgium, Cat no. 61-7300, 1/200), $Y$-Tubulin (Abcam, Cat no. ab11317, 1/500) and GFAP (Millipore, Cat no. AB5804, 1/1000).

\section{In utero electroporation}

E14.5 embryos were electroporated with $1 \mu \mathrm{g}$ pCAG-Gfp and collected at e15.5. Injection needles were pulled from Wiretrol II glass capillaries (Drummond Scientific, Broomall, PA, USA) and calibrated for $1 \mu$ injections. Plasmid DNAs were resuspended in $10 \mathrm{~mm}$ Tris, pH 8.0, with $0.01 \%$ Fast Green. Forceps-type electrodes (Nepagene, Sonidel, Dublin, Ireland) with $5 \mathrm{~mm}$ pads were used for electroporation (five $50 \mathrm{~ms}$ pulses of $25 \mathrm{~V}$ at E12.5 or five $50 \mathrm{~ms}$ pulses of $40 \mathrm{~V}$ at E14.5). Newborn (P0) mice were electroporated with a pcx-Gfp plasmid as previously described.

\section{Real-time PCR}

Total mRNA was isolated from e14.5 telencephalon using RNeasy mini kit according to the supplier's instructions. Reverse transcription was carried out using a RT cDNA synthesis Kit, $1 \mu \mathrm{g}$ of total RNA in a total reaction volume of $20 \mu \mathrm{l}$ (Qiagen, Antwerp, Belgium), SYBR green super mix, and an iCycler real-time PCR detection system (Bio-Rad, Gent, Belgium).

\section{FACS}

For aNPC sorting experiments, cortices of e14.5 control and mutant were processed in parallel. Single cell suspensions were produced using the MACS Neural Tissue Dissociation kit containing papain (MiltenyiBiotec, Paris, France) following the manufacturer's instructions. Cell viability (typically $>95 \%$ ) was assessed with Trypan blue staining. Cell surface staining of CD133 (prominin1) was performed on cell suspensions with rat anti-13A4-APC conjugated (1:100, eBioscience, Brussels, Belgium, Clone 13A4). Cells were incubated with CD133 antibody on ice for $60 \mathrm{~min}$ in PBS (1000 $\mu$ l final volume per brain). Rat IgG-APC (1:100, eBioscience) was used as isotype controls. Cells were sorted according to their APC staining. FACS were performed on a BD FACSAria III sorter (BD Bioscience), and analyzed using the FACS Diva software (BD Bioscience).

\section{Stranded RNA-Seq on purified aNPC}

Total RNA from FACS purified e14.5 CD133-positive aNPC was extracted using Reliaprep RNA miniprep system (Promega, Leiden, Netherlands). Two brains of each genotype were pooled to get one biological replicate. The sequencing was performed by Beckman Coulter Genomics. Total RNA was further purified by ribodepletion and CDNA synthesis and library construction was performed on an automated Illumina TruSEQ stranded RNA-Seq library construction with a Biomek liquid handling platform. Detection of sequencing fragments was performed using the Illumina HiSeq 2500 platform. Alignment was made with Bowtie/Tophat, gene counts with Cufflinks and expression values/differential expression with edgeR. The sequencing output was on average $70.10^{6}$ reads per sample.

\section{Quantification}

For quantification on coronal sections, pictures were acquired so as to cover the entire VZ/SVZ (subventricular zone) or all cortical layers. Both hemispheres were analyzed. ImageJ was used for counts and measurements.

\section{Statistics}

For pairwise analysis of treatment conditions or genotypes, Student's ttests were used. For three chamber test, one-way analysis of variance (ANOVA) was used. For cell population quantification during development, effect of treatment on different genotypes and water maze, two-way ANOVA and Bonferoni post-test were used. Data are represented as mean \pm s.e.m. Chi contingency test was used for distribution analyses.

\section{RESULTS}

Loss of Celsr1 promotes self-renewal of progenitors at the expense of neurogenesis

Celsr1 mRNA is specifically expressed by neural progenitors in mouse and human germinal zones ${ }^{13}$ (Supplementary Figure $1 \mathrm{a}, \mathrm{b}$; adapted from http://brainspan.org ${ }^{14}$ ). We used a tamoxifen inducible system to label aNPC and trace their progeny. Tamoxifen was injected to pregnant females at e13.5, and Celsr ${ }^{-1-} ;$ Nestin $^{\text {CreERT2, }}$ loxP-stop-loxP-dTomato embryos were collected at e14.5 and compared to control littermates $\left(\mathrm{Celsr} \mathrm{1}^{+/+}\right.$;Nestin ${ }^{\text {CreERT2}}$;loxP-stoploxP-dTomato). Mutant aNPC generated more Tomato-positive cells 
Electroporation@e14.5 to e15.5
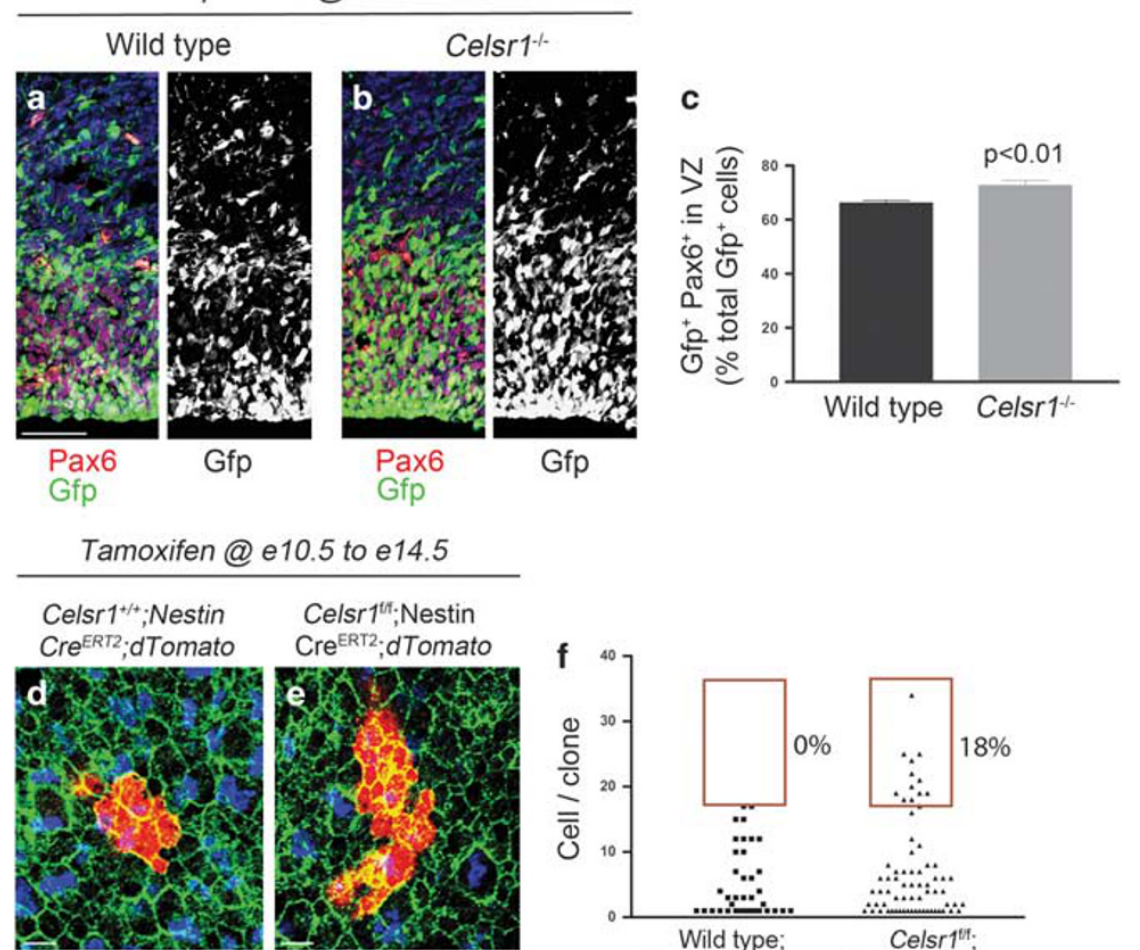

Tomato Beta-Catenin
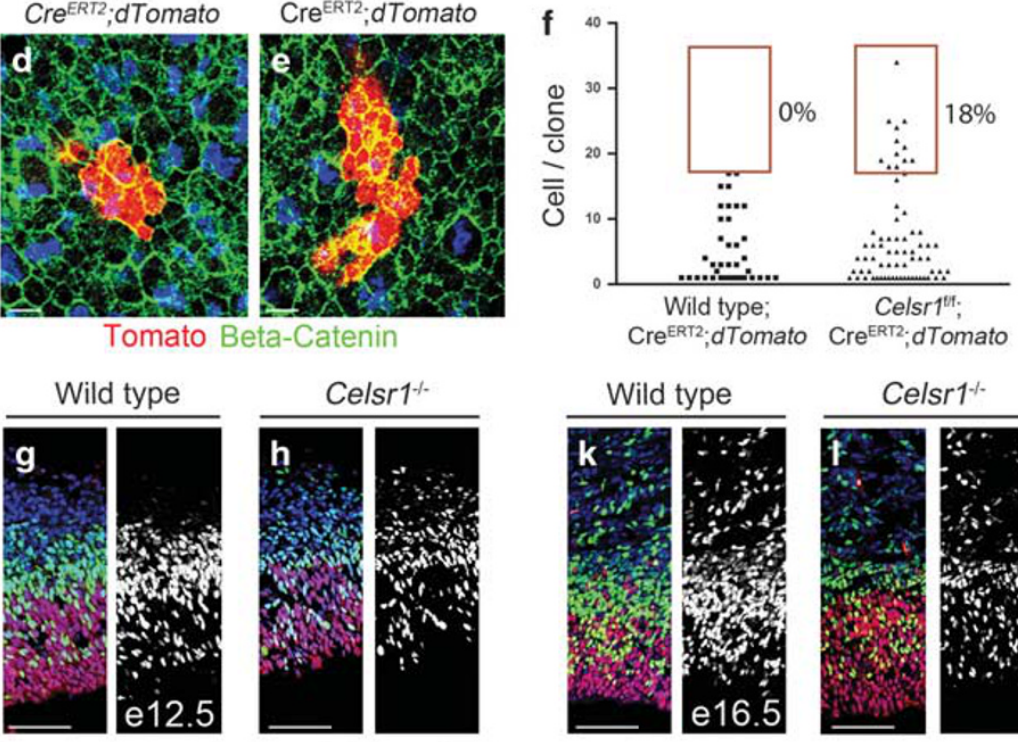

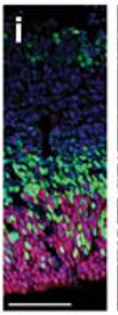

Pax6

Tbr2

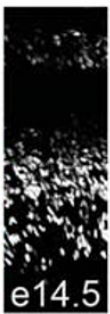

Tbr2

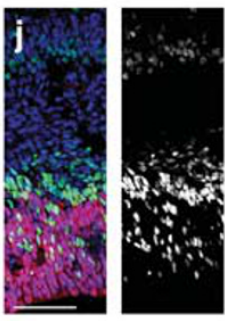

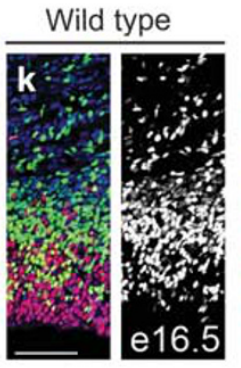
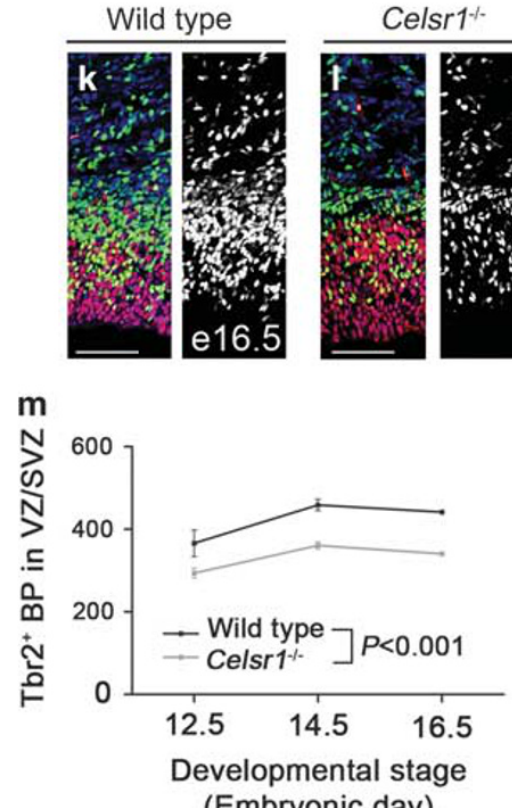

Figure 1. Cortical phenotype of Celsr1 mutant mice. (a-c) Pax6 (red) and Gfp (green) staining of coronal brain sections from wild type (a) and Celsr $1^{-1-}$ (b) embryos, electroporated with a Gfp-coding plasmid at e14.5 and collected at e15.5. Scale bars $50 \mu \mathrm{m}$. (c) Quantification of Gfppositive cells residing in the VZ, $24 \mathrm{~h}$ after electroporation. $n=4$ brains for each genotype, error bars are s.e.m., Student's $t$-test, $P<0.01$. (d-f)

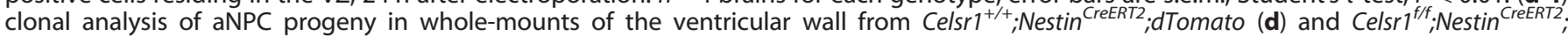
dTomato (e) Scale bars $50 \mu \mathrm{m}$. (f) Quantification of the number of cells per clone. $18 \%$ of mutant clones have more than 17 cell per clone (0 \% in controls), $n=6$ whole-mounts for each genotype. (g-I) Immunochemistry for aNPC (Pax6) and BPs (Tbr2) at e12.5 (g, h), e14.5 (i, j) and e16.5 $(\mathbf{k}, \mathbf{I})$. Scale bars $50 \mu \mathrm{m}$. (m) Quantification of Tbr2-positive cells in lateral pallium at indicated stages. $n=3$ brains per stage and per genotype, bars represent s.e.m., two-way ANOVA, $P<0.001$.

in the VZ and less cells in the SVZ than controls (Supplementary Figure $2 a-c$; percentage of Tomato ${ }^{+}$cells in VZ: Wild type $=53.6 \%$, Celsr $1^{-1-}=70.2 \%, n=3, P=0.0008$, Student's $t$-test). This observation was corroborated by in utero electroporation of a Gfp coding plasmid at e14.5, which disclosed an accumulation of Gfp- and
Pax6-positive cells in the mutant versus control VZ at e15.5 (Figures 1a-c, percentage of Pax $6^{+}$cells in Gfp cell population: Wild type $=66.3 \%$, Celsr ${ }^{-/-}=72.7 \%, n=4, P=0.0064$, Student's $t$-test). To further investigate the effect of Celsr1 loss-of-function on fate decision, we injected low concentrations of tamoxifen to mice 

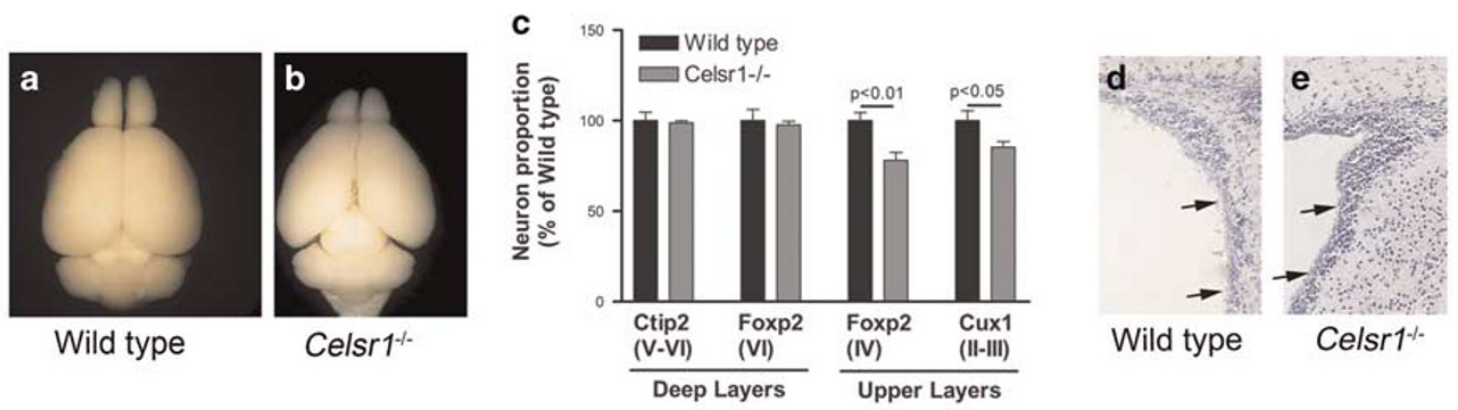

Wild type Celsr ${ }^{\%}$

Open field:Male

EPM:Male
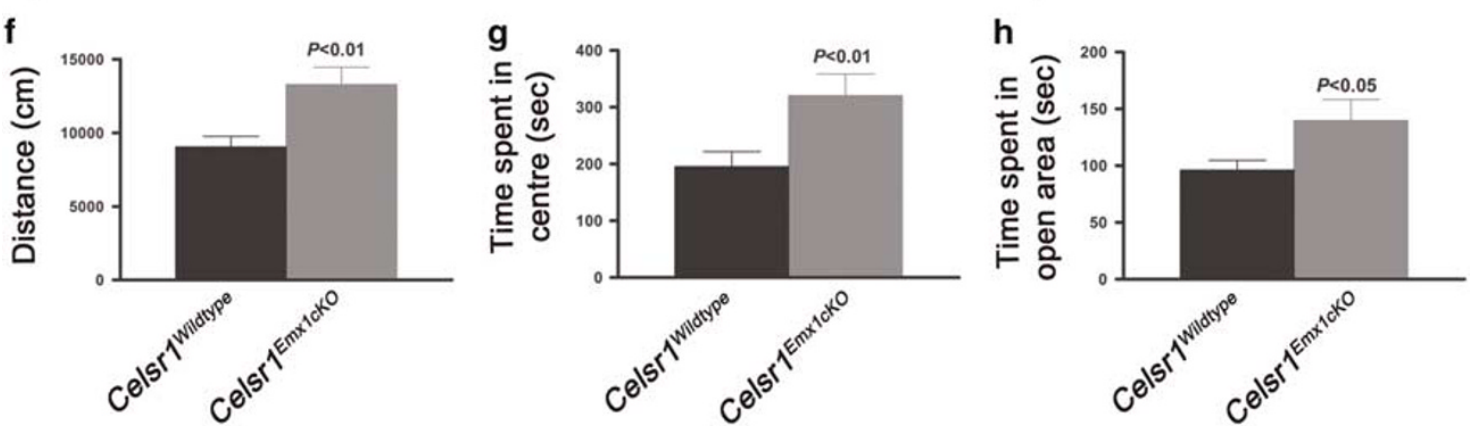

i

Water maze:Male

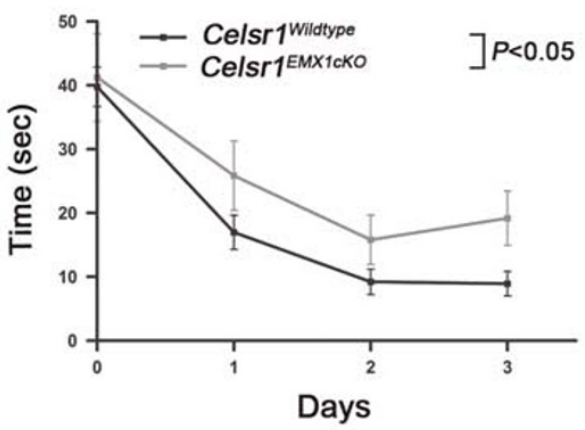

j

3 chambers test: Male

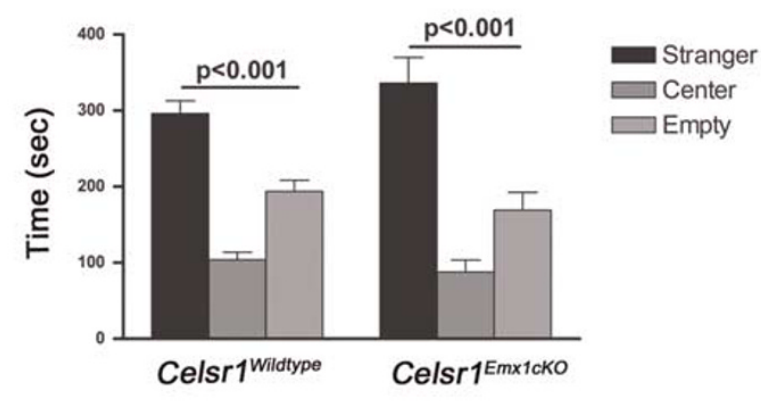

Open field:Female

EPM:Female
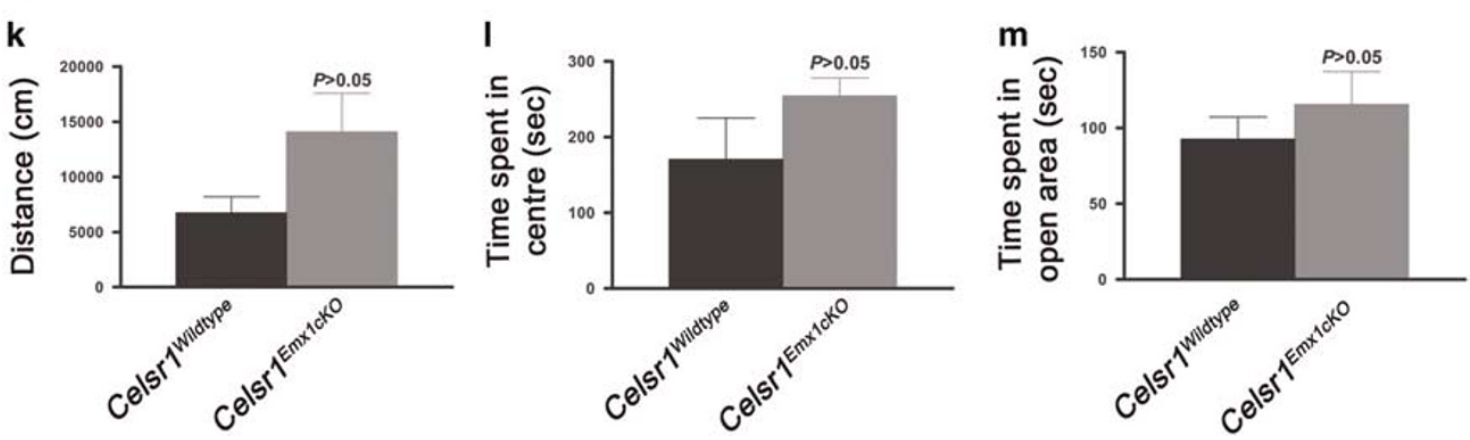

Figure 2. Cortical hypoplasia and abnormal behavior in Celsr1-deficient mice. (a, b) Mature brains from Wild type (a) and Celsr1 ${ }^{-/-}$(b) mice. Note the reduced size in the mutant. (c) Quantification of neurons of different cortical layers. $n=3$ brains per genotype, bars represent s.e.m., Student's $t$-test, $P<0.05$ for Cux1-positive cells (layers II and III); and $P<0.01$ for Foxp2-positive cells (layer IV). The number of cells in the Wild type is set to $100 \%$. (d, e) Nissl staining of the adult VZ/SVZ in wild type (d) and Celsr $1^{-1-}$ (e). (f, $\left.\mathbf{g}\right)$ Activity of males in open field. Bars represent s.e.m., Student's $t$-test, $P<0.01$. (h) Time spent by males in open areas of elevated plus maze (EPM). Bars represent s.e.m., Student's $t$-test, $P<0.05$; (i) Learning ability of males in the Water maze. Bars represent s.e.m., Student's $t$-test, $P<0.05$. (j) Social behavior in the ' 3 chamber' test for males. Bars represent s.e.m., one-way ANOVA, $P<0.001$ for both genotypes (stranger versus empty chamber). (k, I) Activity of females in open field. Bars represent s.e.m., Student's t-test, $P>0.05$. (m) Time spent by females in open areas of elevated plus maze. Bars represent s.e. m., Student's $t$-test, $P>0.05$. (n) Learning ability of females in the Water maze. Bars represent s.e.m., Student's $t$-test, $P>0.05$ (o) Social behavior in the ' 3 chamber' test for females. Bars represent s.e.m., one-way ANOVA, $P<0.001$ control females, $P>0.05$ for mutant females (stranger versus empty chamber). $n=14$ controls (Celsr ${ }^{+/+} ; E m x 1$-Cre: nine males, five females), $n=10$ Celsr ${ }^{\text {EmxicKO }}$ (five males, five females). 
n

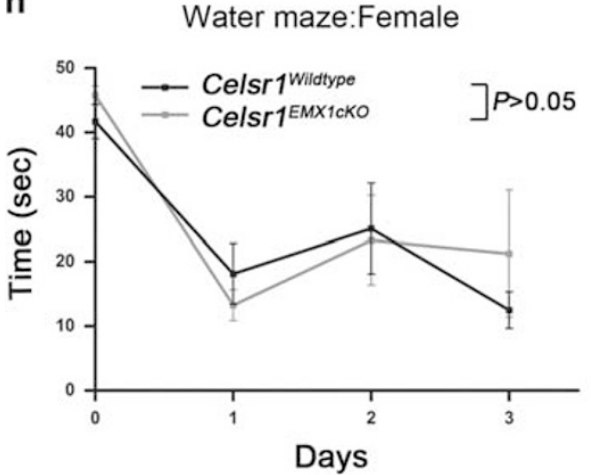

0

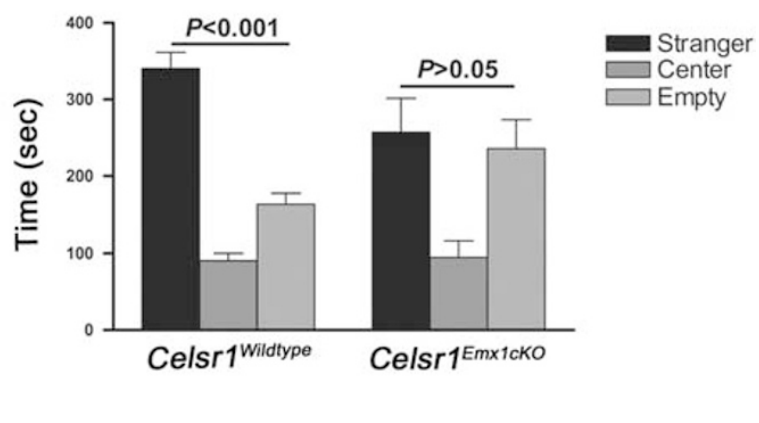

Figure 2. Continued

carrying a floxed allele $\left(\mathrm{Celsr}{ }^{f}\right)$ at e10.5, with the aim to inactivate the gene in sparse aNPC and enable a clonal analysis. Examination of the ventricular surface at e14.5 detected larger clones in conditional mutants (Celsri ${ }^{\text {f/f }} ;$ Nestin ${ }^{\text {CreERT2 }}$;loxP-stop-loxP-dTomato)

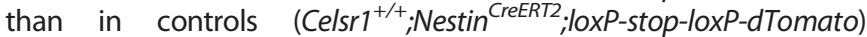
(Figures 1d-f).

These results suggest that Celsr1-deficient aNPC undergo more symmetric, proliferative divisions than their control counterparts, leading to accumulation of aNPC (Pax6 $6^{+}$cells) in the VZ. Reasoning that this could disrupt the radial versus tangential expansion of the developing cerebral cortex, we measured the length of the VZ (which reflects the expansion of the pool of progenitors) and found that it was similar in mutant and control embryos at e10.5, but increased significantly in mutant samples from e12.5 onwards (Supplementary Figure 2d, e, $n=3$ brains per genotype and per stage, $P<0.001$, two-way ANOVA). This increase resulted in a local distortion of the VZ at e16.5 (Supplementary Figure 2f, g), and correlated with a higher number of Pax6-positive aNPC in the VZ (Wild type $=410.7 \pm 11.3$, Celsr $^{-/-}=452 \pm 14.5, n=3$ brains per stage and per genotype, $P<0.01$, two-way ANOVA; Supplementary Figure $2 \mathrm{~h}$ ). During corticogenesis, aNPC produce $\mathrm{Tbr}^{+} \mathrm{BP}$, which divide in the SVZ to scale up neuron production. Concomitant to the increased number of aNPC progenitors, the number of Tbr2-positive BP decreased in mutants (Figures $1 \mathrm{~g}-\mathrm{m}$, Supplementary Figure $3 a-n)$. The reduction of BPs was significant starting from e12.5 in the lateral pallium (Figure $1 \mathrm{~m}, \mathrm{Tbr}^{+}$cells in VZ/SVZ, wild type $=366 \pm 72.6, \quad$ Celsr $1^{-1-}=293.8 \pm 49.3, n=3$, $P<0.001$, two-way ANOVA), and from e14.5 in the dorsal pallium (Supplementary Figure $3 \mathrm{n}, \mathrm{Tbr}^{+}$cells in VZ/SVZ, Wild type $=$ $351.8 \pm 67.8, \quad$ Celsr1 ${ }^{-1-}=307.9 \pm 26.5, \quad n=3, P<0.05$, two-way ANOVA). This was further confirmed by the observation of a decreased number of mitotic, Phospho-Vimentin ${ }^{+}$cells in the SVZ at e14.5 (Supplementary Figure 4a-f, dorsal pallium: wild type = $4.2 \pm 0.5$, Celsr $^{-1-}=2.3 \pm 0.4, n=3, P=0.0185$, Student's $t$-test; lateral pallium: Wild type $=3.2 \pm 0.5, \mathrm{Celsr}^{-/-}=1.5 \pm 0.3, n=3$, $P=0.0046$, Student's $t$-test).

\section{Celsr1-deficient aNPC produce more adult NSCs}

According to their localization in the developing telencephalon, aNPC cells produce cortical or striatal neurons. To test whether the effect of Celsr1 on fate decision is region specific, we characterized other neurogenic areas in the developing and adult brain. In absence of Celsr1, aNPC in ganglionic eminences, which generate striatal neurons and cortical interneurons, underwent more proliferative divisions than control ones, as illustrated by: (i) Increased number of Sox2-positive cells (Supplementary Figure $5 \mathrm{a}-\mathrm{e}$, Sox $2^{+}$cells in VZ/SVZ at e12.5: wild type $=207 \pm 5.9$, Celsr $1^{-1-}$ $=271.3 \pm 11.7, n=3$; at e16.5: Wild type $=96.2 \pm 5.6$, Celsr1 ${ }^{-/-}=$ $161.9 \pm 5.6, n=3, P<0.0001$, two-way ANOVA); (ii) Decreased number of Mash $1^{+}$BPs (Supplementary Figure $5 a-d, f$, Mash $1^{+}$ cells in VZ/SVZ at e12.5: wild type $=340.7 \pm 7.2, \mathrm{Celsr}^{-1-}=$ $312 \pm 9.6, n=3 ;$ at e16.5: wild type $=128 \pm 5.8, \quad \mathrm{Celsr}^{-/-}=$ $110.3 \pm 5.9, n=3, P<0.002$, two-way ANOVA); and (iii) Narrowing of the intermediate zone containing Dl $\times 5 / 6^{+}$postmitotic neurons (Supplementary Figure $5 \mathrm{~g}-\mathrm{i}$, width of Dlx5/6-Gfp ${ }^{+}$area at e16.5, wild type $=283.3 \pm 3.3 \mu \mathrm{m}$, Celsr1 ${ }^{-/-}=234 \pm 4.9 \mu \mathrm{m}, n=3$, $P=0.0005$, Student's $t$-test).

In addition to postmitotic neurons, B1 cells, a pool of neural progenitors that remain quiescent until reactivation in the adult brain, are mainly derived from aNPC during early neurogenesis. ${ }^{15}$ In the adult VZ/SVZ, B1 cells display an epithelial apicobasal organization reminiscent of aNPC cells. The morphology of these cells was similar in Celsr1 mutants and controls. Following electroporation at early postnatal stages, Gfp-filled B1 cells extended from the ventricle apically (Supplementary Figure 6a, b) to the VZ/SVZ blood vessel plexuses basally (Supplementary Figure $6 c$, d). Similarly, B1 cells exhibited apical processes abutting the ventricle (Supplementary Figure $6 \mathrm{e}, \mathrm{f}$ ) and basal endfeet lining blood vessels (Supplementary Figure $6 \mathrm{~g}, \mathrm{~h}$ ) at P90. Whole-mount staining of the ventricular lateral wall showed that B1 cells expressing GFAP were surrounded by ependymal GFAP-negative cells (Supplementary Figure 6e, f), forming the so called pinwheel structure. ${ }^{16}$ Contrary to ependymal multiciliated cells, B1 cells are decorated by a single cilium. We used the basal body marker $\gamma^{-}$ tubulin to visualize the pinwheels and found that these structures were more abundant in mutant than in control mice at P30 and P90. (mean number of pinwheels per field $\left(0.044 \mathrm{~mm}^{2}\right)$ in the dorso-lateral wall at P30: Wild type $=16.6 \pm 1.3, \mathrm{Celsr}^{-/-}$ $=28.2 \pm 1.5, n=6$ whole mounts, $P=0.0004$, Student's $t$-test, Supplementary Figure 7a-e; at P90: wild type $=7.5 \pm 0.8, \mathrm{Celsr}^{-/-}$ $=12.8 \pm 1.5, n=6$ whole mounts, $P=0.0016$, Student's $t$-test, Supplementary Figure $7 \mathrm{~h}-\mathrm{q}$ ). In addition, the mutant lateral wall contained larger clusters of B1 cells than control, both at P30 (Supplementary Figure 7f) and P90 (Supplementary Figure 7r); leading to a dramatic increase of the density of adult NSC (number of NSC per field in the dorso-lateral wall at P30: wild type $=39.6$ \pm 3.9 , Celsr $1^{-1-}=104.4 \pm 7, \quad n=6$ whole mounts, $P<0.0001$; Student's $t$-test, Supplementary Figure $7 \mathrm{~g}$; at P90: Wild type $=$ 16.4 \pm 1.7, Celsr1 $1^{-1-}=47.1 \pm 5, n=6$ whole mounts, $P<0.0001$, Student's $t$-test, Supplementary Figure $7 \mathrm{~s})$. Thus, in Celsr 1 mutants, aNPC produce more adult NSCs (B1 cells), and less neurons than in controls.

Celsr1 mutant mice have cortical hypoplasia and disturbed behavior

We measured brain weight at P0, P4, P8, P10 and P12, and found significant differences between Celsr $1^{-/-}$and controls starting from P4 (Supplementary Figure 8a; wild type $=171 \pm 7.6 \mathrm{mg}$, Celsr ${ }^{-1-}=138.6 \pm 2.5 \mathrm{mg}, P=0.0002, n=15$, Student's $t$-test). At $\mathrm{P} 90$, the hypoplasia was particularly apparent in cerebral cortex 


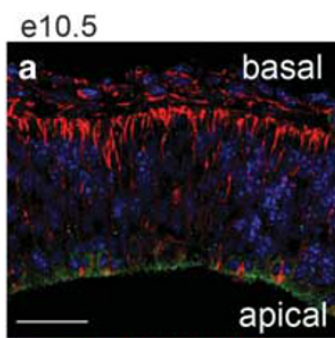

Celsr1 pVimentin

e12.5

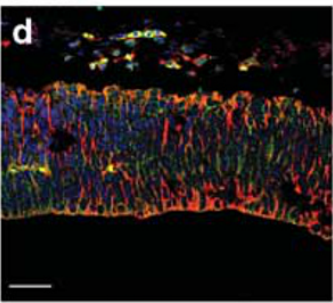

Celsr1 Nestin

e16.5

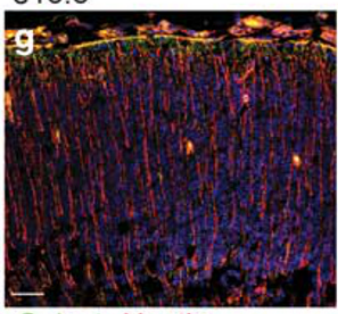

Celsr1 Nestin

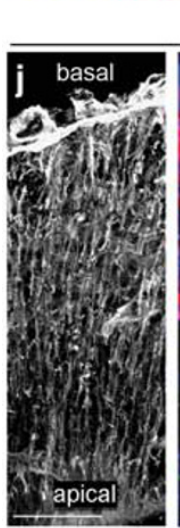

Nestin

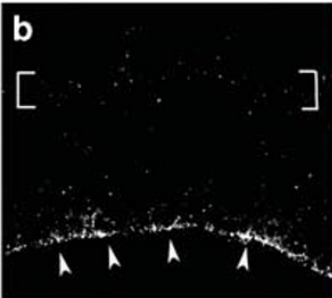

Celsr1

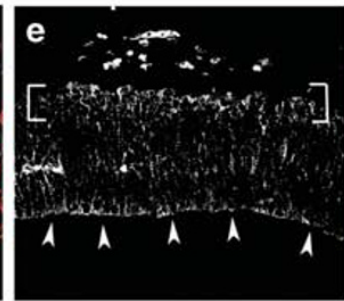

Celsr1

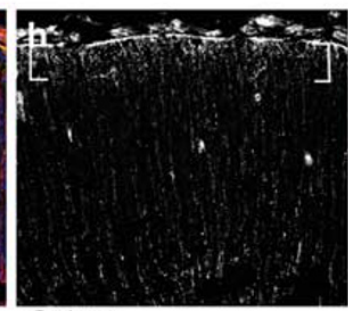

Celsr1
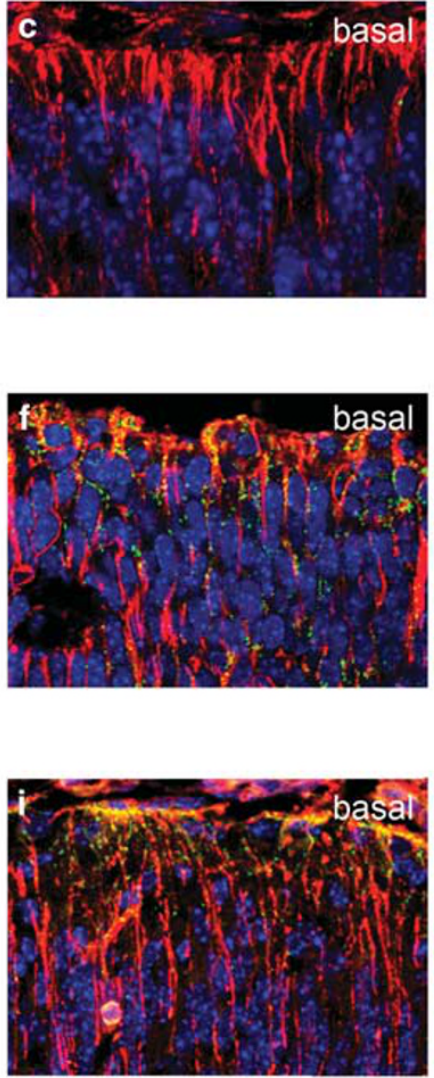

Celsr1\%

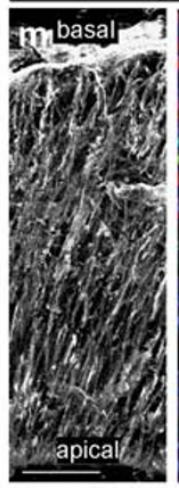

Nestin

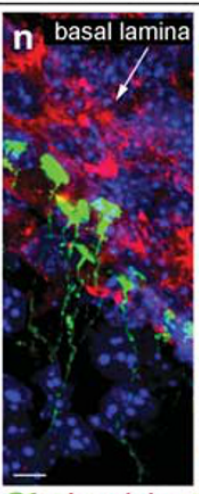

Gfp Laminin Laminin Tuj-1
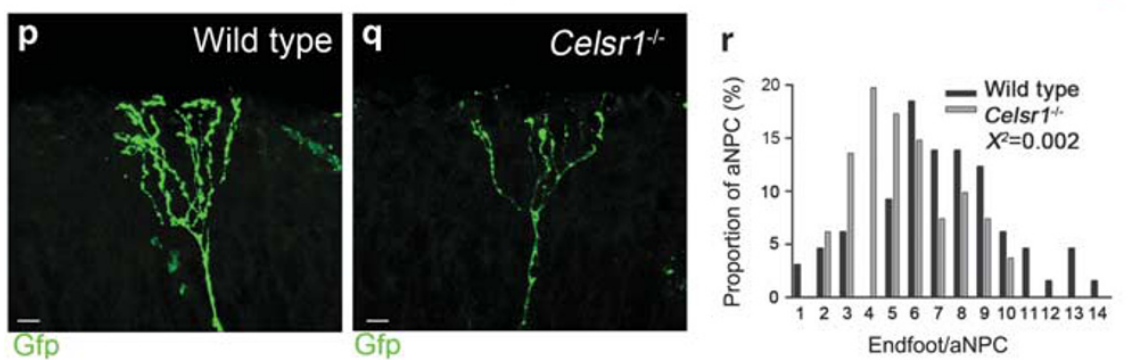

Figure 3. Celsr1 expression during cortical development. (a-i) Coronal sections stained for Celsr1 (green, white), and Phospho-Vimentin (pVimentin, a-c) or Nestin (d-i) (red). At e10.5 (a-c), Celsr1 protein localizes at the apical side (arrowheads) but not in endfeet (brackets). Scale bars $50 \mu \mathrm{m}$. At e12.5 (d-f) and e16.5 (g-i), Celsr1 is distributed both in apical and basal compartments. Scale bars $50 \mu \mathrm{m}$. (j-o) Coronal sections

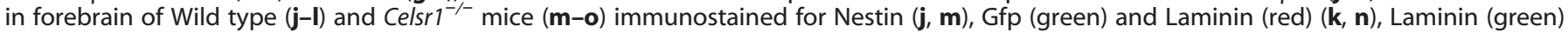
and Tuj-1 (red) (I, o). Note the intact basal lamina (arrowheads). Scale bars $50 \mu \mathrm{m}(\mathbf{j}, \mathbf{m}), 10 \mu \mathrm{m}(\mathbf{k}, \mathbf{n}), 100 \mu \mathrm{m}(\mathbf{l}, \mathbf{0})$. (p, r) Gfp-filled basal processes of aNPC from Wild type (p) and Celsr1 ${ }^{-1-}$ mice (q). Note the simplified morphology in the mutant. Scale bars $20 \mu \mathrm{m}$. (r) Quantification of endfeet in Wild type and Celsr1 ${ }^{-/-}$mice at P1. $n=65$ aNPC for Wild type, and 81 for Celsr1 ${ }^{-/-}$; Chi square test, $X^{2}=0.002$. 


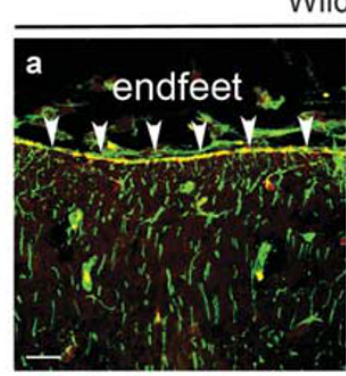

Crabp2 Nestin

Prominin-positive cells
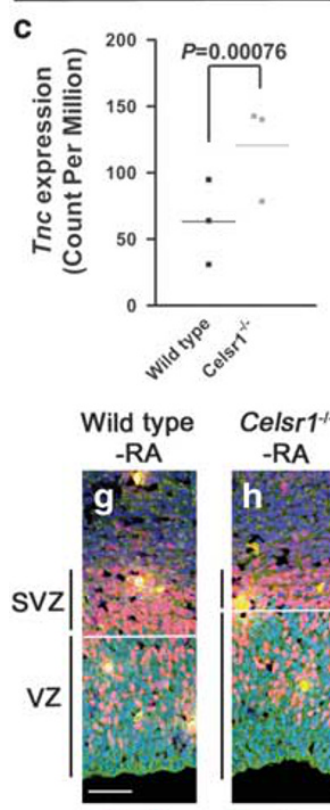

Tbr2

Celsr $1^{\%}$
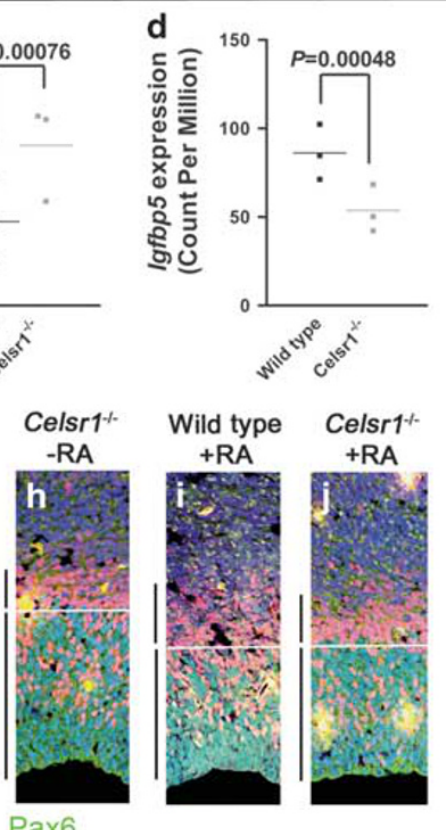

Pax6

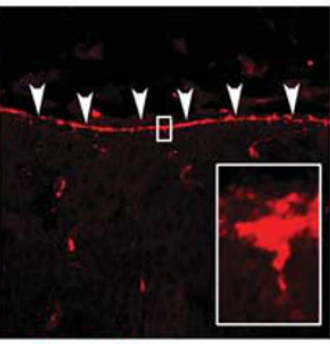

Crabp2

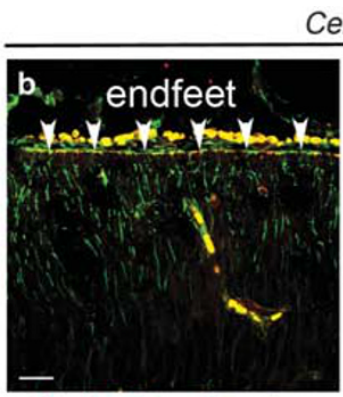

Crabp2
Celsr $1 \%$

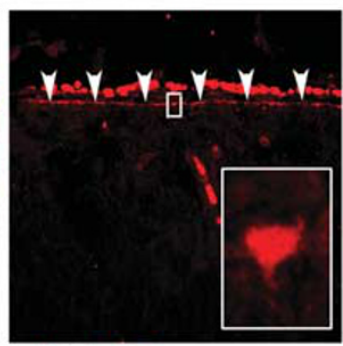

Crabp2

Telencephalon
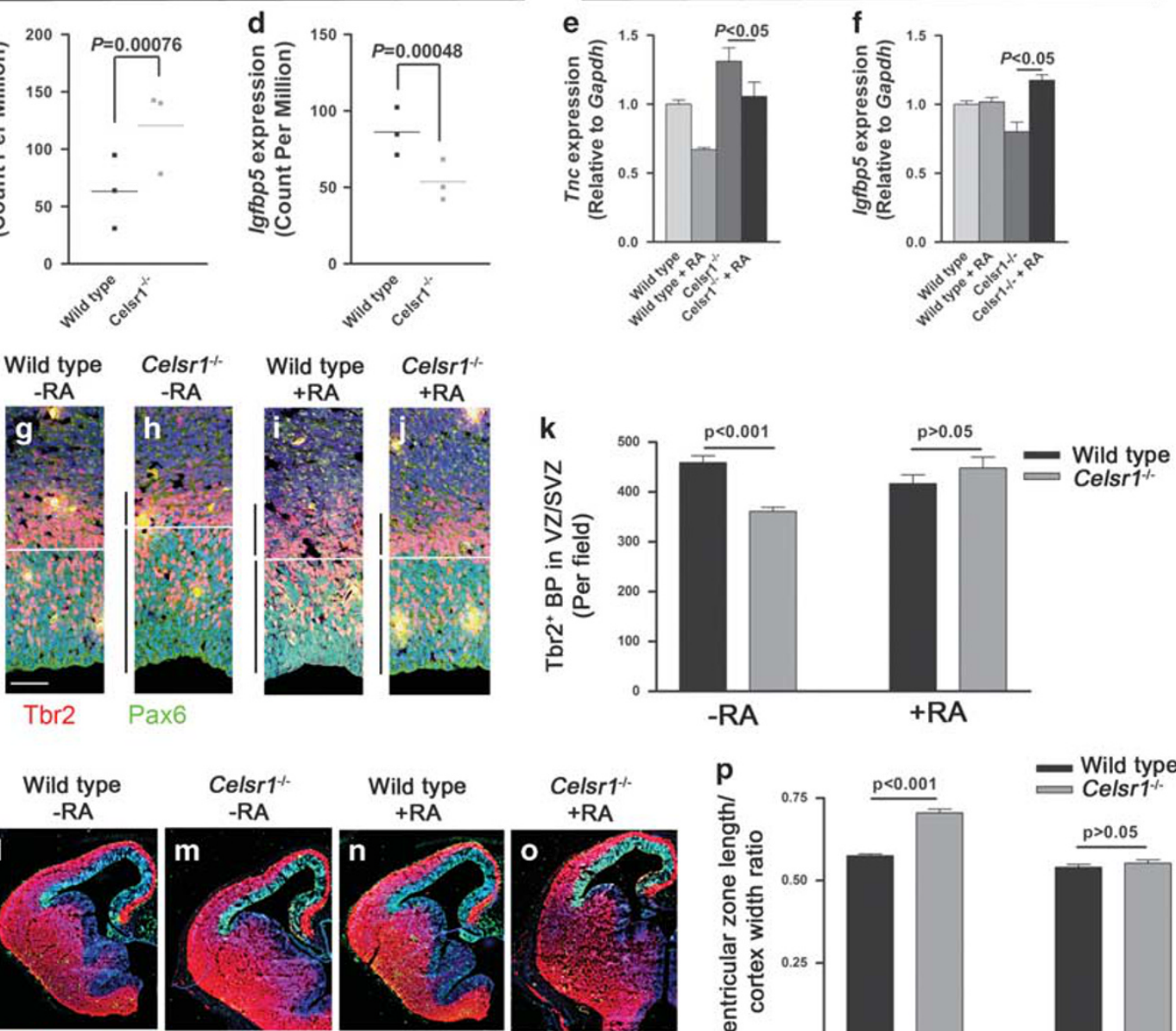

Tuj1

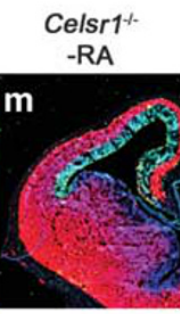

ax6

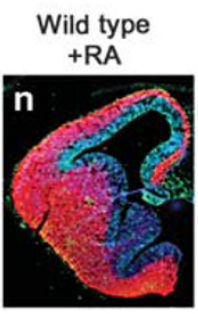

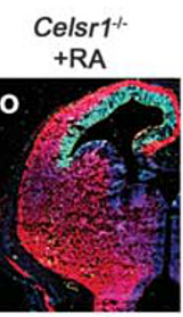

p
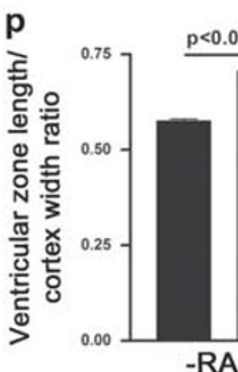

Wild type

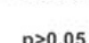

Figure 4. RG endfeet modulate the RA neurogenic signal. (a, b) The RA shuttle protein Crabp2 is enriched in aNPC endfeet. Scale bars $50 \mu$ m (c-f) Modification of transcription of RA target genes Tnc and lgfbp5 revealed by RNA-Seq on isolated aNPC (c, d) and confirmed by qRT-PCR on e14.5 telencephalon (e, f). $n=3$ brains for RNA-Seq and four brains for qRT-PCR. Bars represent s.e.m. Two-way ANOVA for qRT-PCR. (g-p) RA supplementation from e11.5 to e14.5 rescues the production of BPs $(\mathbf{g}-\mathbf{k})$ and lateral expansion of the VZ (I-p). $n=4$ embryos per condition. Bars represent s.e.m. Two-way ANOVA, $P<0.001$ without RA and $P>0.05$ with RA.

and cerebellum, with unmasking of the superior and inferior colliculi (Figures 2a, b). Immunolabeling using layer specific markers showed a reduction in the number of Foxp2 ${ }^{+}$and $\mathrm{Cux}^{+}$neurons (Figure 2c, number of Foxp2 ${ }^{+}$cells (wild type $=$ $341 \pm 15.3$, Celsr $1^{-1-}=266 \pm 15.1, \quad n=3, P=0.0083$; number of $\mathrm{Cux}^{+}$cells: wild type $=644.4 \pm 34.8, \mathrm{Celsr}^{-/-}=550 \pm 20, n=3$, $P=0.0467$, Student's t-test). In addition, histological examination of brain sections revealed that Celsr $1^{-/-}$mice displayed a thicker VZ/SVZ (Figures 2d, e). Celsr1 ${ }^{-/-}$adult mice exhibited turning behavior, a distinctive feature of inner ear/vestibular system dysfunction (Supplementary Movie 1). To investigate further the impact of loss of Celsr1 on cortical development, we selectively inactivated Celsr1 in neocortical areas by crossing mice carrying the Celsr ${ }^{f}$ allele with Emx1-Cre mice. Like the constitutive mutants, Celsr ${ }^{f / f} ; E m x 1-C r e$ conditional knockout mice (hereafter referred to as Celsr1 ${ }^{\text {Emx1CKO})}$ displayed smaller cortices than controls $\left(\mathrm{Celsr}{ }^{+/+} ; \mathrm{Emx} 1-\mathrm{Cre}\right)$ (Supplementary Figure $8 \mathrm{~b}-\mathrm{e}$, weight of the Emx1-Cre-Tomato+ area: control males $=87 \pm 3.3 \mathrm{mg}$, Celsr 1 Emx1cKO males $=75 \pm 9.9 \mathrm{mg}, \quad n=3, \quad P=0.0256$; control females $=$ $75.6 \pm 4.2 \mathrm{mg}$, Celsr1 ${ }^{\text {Emxicko }}$ females $=59.1 \pm 2.4 \mathrm{mg}, \quad n=4$, $P=0.0138$, Student's $t$-test). We assessed the impact of these morphological changes on behavior. Celsr $1^{\operatorname{Em} \times 1 C K O}$ mice exhibited 

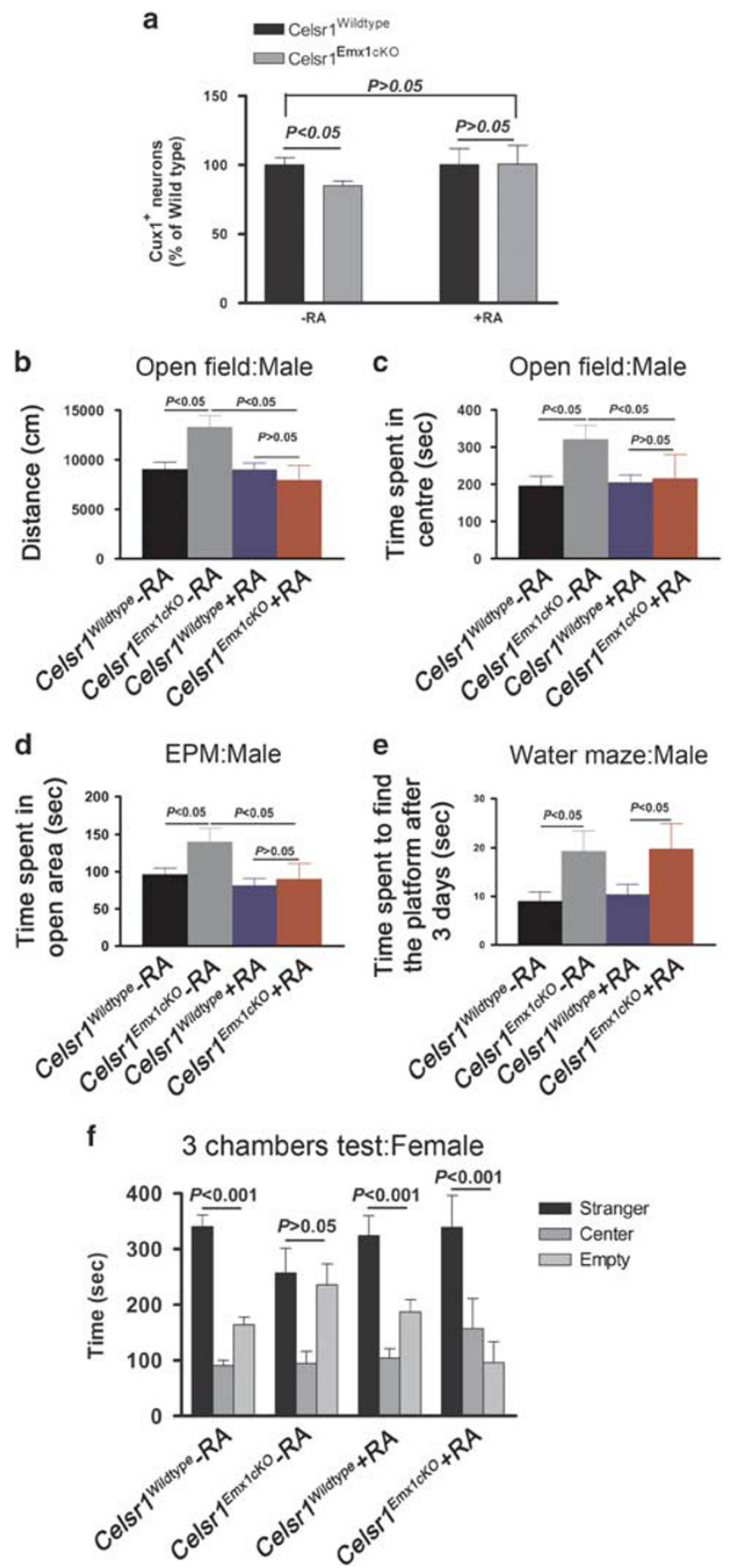

gender-specific defects in activity, attention, anxiety, spacial learning and social interactions (Figures $2 \mathrm{f}-\mathrm{o}$ ). Males displayed more spontaneous motor activity and spent more time than controls in exposed areas in open field and elevated plus maze (distance covered in open field: controls $=8220 \pm 726.2 \mathrm{~cm}$, Celsr1 ${ }^{\text {Emx1CKO }}=13670 \pm 1747 \mathrm{~cm}, \quad n=14$ controls and 10 Celsr1 ${ }^{\text {Emx1cKO }}, P=0.0040$, Student's $t$-test, Figure $2 f$; time spent in exposed areas in open field: controls $=186.7 \pm 24.7 \mathrm{~s}$, Celsr ${ }^{\text {Emx1CKO }}=287.5 \pm 23.7 \mathrm{~s}, \quad P=0.0096, \quad$ Student's $t$-test Figure 2g; time spent in open area in elevated plus maze, controls $=94.95 \pm 7.2 \mathrm{~s}$, Celsr1 ${ }^{\text {Emx1cKO }}=127.6 \pm 14 \mathrm{~s}, P=0.0352$, Student's $t$-test, Figure $2 \mathrm{~h}$ ). The hiding behavior defect suggests
Figure 5. Effect of RA supplementation on cortical development and behavior in Celsr1 Emx1ckO mice. (a) Quantification of Cux1-positive neurons (layers II and III) in Celsr1 ${ }^{\text {wildtype }}$, Celsr1 ${ }^{\text {Emx } 1 \mathrm{CKO}}-\mathrm{RA}$ and Celsr1 ${ }^{\mathrm{Em} \times 1 \mathrm{CKO}}+$ RA. $n=5$ brains per genotype; bars represent s.e.m.; Student's $t$-test; Celsr $1^{\text {Wildtype }}$ versus Celsr $1^{\text {Emx } 1 \text { CKO }}$-RA, $P<0.05$; Celsr $1^{\text {Wildtype }}$ versus Celsr1 ${ }^{\mathrm{Em} \times 1 \mathrm{cKO}}+\mathrm{RA}, P>0.05$. The number of cells in the Wild type is set to $100 \%$. (b) Locomotor activity of males in open field. Bars represent s.e.m.; Student's $t$-test; Celsr 1 Wildtype versus Celsr1 ${ }^{\text {Emx1cKO }}$-RA, $P<0.05$; Celsr1 $1^{\text {Wildtype }}$ versus Celsr1 ${ }^{\text {Emx1cKO }}+$ RA, $P>0.05$. (c, d) Time spent by males in exposed areas of open field (c) and open arms of elevated plus maze (d). Bars represent s.e.m., Student's $t$-test, Celsr1 $1^{\text {Wildtype }}$ versus Celsr1 ${ }^{\text {Emx } 1 \mathrm{CKO}}$-RA, $P<0.05$; Celsr1 $1^{\text {Wildtype }}$ versus Celsr $1^{\text {Emx1cKO }}+$ RA, $P>0.05$; (e) Learning ability of males in the water maze. Bars represent s.e.m., Student's t-test, Celsr $1^{\text {Wildtype }}$ versus Celsr $1^{\text {Emx1CKO }}{ }_{-R A}, P<0.05$; Celsr $1^{\text {Wildtype }}$ versus Celsr1 ${ }^{\mathrm{Em} \times 1 \mathrm{cKO}}+\mathrm{RA}, P<0.05$. (f) Social behavior in the ' 3 chamber' test for females. Bars represent s.e.m., one-way ANOVA, $P>0.05$ for Celsr1 ${ }^{\text {Emx1cKO }}$-RA (stranger versus empty chamber); $P<0.001$ for Celsr1 ${ }^{\text {Wildtype }}$ and Celsr1 ${ }^{\mathrm{Em} \times 1 \mathrm{CKO}}+\mathrm{RA}$ (stranger versus empty chamber). For the RA rescue experiments, $n=9$ animals per genotype and per condition.

attention and or anxiety deficit in addition to hyperactivity. Males also exhibited a spatial learning deficit in the water maze setup (time spent to find the platform controls at day $3=8.9 \pm 1.9 \mathrm{sec}$, Celsr1 ${ }^{\text {Emx1CKO }}=19.2 \pm 4.2 \mathrm{sec}, \quad n=5-9$ animals per genotype, $P<0.05$, two-way ANOVA, Figure 2i), but no social behavior defect in the 'three-chamber' test (time spent in empty chamber controls $=193.9 \pm 14.7 \mathrm{sec}$, with stranger $=296.2 \pm 16.5 \mathrm{sec}$, Celsr ${ }^{\text {Emx1cKO }}$ in empty chamber $=169.1 \pm 23.3 \mathrm{sec}$, with stranger = $336.3 \pm 33.5 \mathrm{sec}, n=5-9$ animals per genotype, $P<0.001$ for both genotype, one-way ANOVA, Figure 2j).

Although mutant females tended to be more active and less anxious than controls, the differences were not statistically significant (distance covered in open field: controls $=6735 \pm 1461 \mathrm{~cm}$, Celsr1 ${ }^{\text {Emx1cKO }}=14070 \pm 3505 \mathrm{~cm}, n=5$ per genotype, $P=0.0894$, Student's $t$-test, time spent in exposed areas in open field: controls $=170.6 \pm 54.5 \mathrm{~s}$, Celsr ${ }^{\text {Emx1cKO }}=254.4 \pm 23.7 \mathrm{~s}$, $P=0.1963$, Student's $t$-test, Figures $2 \mathrm{k}, \mathrm{l}$ ), elevated plus maze (time spent in open area in elevated plus maze, controls $=92.74 \pm 14.6 \mathrm{~s}$, Celsr1 ${ }^{\text {Emx1CKO }}=115.6 \pm 21.6 \mathrm{~s}, \quad P=0.4063$, Student's $t$-test, Figure $2 \mathrm{~m}$ ), and water maze (Day $1-3, P>0.05$, two-way ANOVA, Figure $2 \mathrm{n}$ ); Yet, they exhibited a social interaction defect, spending similar time periods in the empty chamber as with the stranger mouse (controls in empty chamber $=164.3 \pm 13.4 \mathrm{~s}$, with stranger $=340.6 \mathrm{~s} \pm 20.8 \mathrm{~s}, n=5, P<0.001 ;$ Celsr ${ }^{\text {Emx1cKO }}$ in empty chamber $=235.8 \pm 37.8 \mathrm{~s}$, with stranger $=257.1 \mathrm{~s} \pm 44.5 \mathrm{~s}, \quad n=5$ animals per genotype, $P>0.05$, one-way ANOVA, Figure 20). This combination of traits has been described in rodent models of attention deficit/hyperactivity disorder (ADHD), ${ }^{17}$ and autism spectrum disorder (ASD), ${ }^{18,19}$ two neurodevelopmental conditions with high co-morbidity. ${ }^{20}$ Taken together, these results suggest that the loss of Celsr1 promotes proliferation of aNPC at the expense of neurogenesis, decreases the number of neurons, leading to cortical hypoplasia and disrupted behavior.

Celsr 1 inactivation modifies the transcriptome of aNPC

To investigate further how Celsr1 controls the balance between proliferation and differentiation of aNPC, we purified control and mutant Prominin-positive cells by FACS at e14.5, extracted RNA and compared their transcriptome using RNA-Seq (Supplementary Figure 9). We found that 276 genes displayed an altered expression in Celsr1-deficient aNPC (Supplementary Table 1, False discovery rate $P<0.01$, fold changes $>1.5$ ). Compared with controls, $20 \%$ of misregulated genes were upregulated, and $80 \%$ were downregulated (Supplementary Figure 9a). Hierarchically clustered gene ontology terms for biological processes 
emphasized genes involved in Wnt/PCP signaling, cilia assembly and movement, brain development and generation of neurons, cell proliferation and differentiation, positive regulation of transmembrane receptor protein serine/threonine kinase signaling pathway, and regulation of cellular response to growth factor stimulus (Supplementary Table 2). Changes in Wnt/PCP, cilia movement and assembly, and microtubule cytoskeleton were predictable given the established role of Celsr1 in PCP and cilia biogenesis, and the relationship between Wnt and PCP..$^{5,8,9}$ On the other hand, several genes involved in Wnt signaling such as Sulf1, Sulf2, GPC3, Rspo1-3 are also implicated in transmembrane receptor protein serine/threonine kinase signaling.

Consistent with the increased proliferation of aNPC in Celsr 1 mutants, we found that $19 \%$ of the upregulated genes promote proliferation (Supplementary Figure 9b). Those include $\operatorname{Tm} b 4 x_{1}{ }^{21}$ Rpl34, ${ }^{22} \mathrm{Nsg2}_{2}{ }^{23} \mathrm{Tnc}^{24} \mathrm{Snh}^{25}{ }^{25}$ Pttg1 (Supplementary Figure 9d), ${ }^{26}$ and Dbi (Supplementary Figure $9 e$ ). ${ }^{27}$ Of note, in humans, the extracellular matrix protein TNC (Tenascin C) is highly expressed in the outer SVZ, a region which, in gyrencephalic brains, contains highly proliferative outer radial glia. ${ }^{24}$ Moreover, Thymosin beta4 (Tmsb4x) strongly promotes proliferation of neural progenitors. ${ }^{21}$ On the other hand, $13 \%$ of the downregulated genes are known tumor suppressors (Supplementary Figure 9c). They include Sulf1, ${ }^{28}$ Sostdc1, ${ }^{29}$ Ccdc67, $^{30}$ Ptprt, $^{31}$ Igfbp5, ${ }^{32}$ Rbm47, ${ }^{33}$ Sepp $1^{34}$ (Supplementary Figure 9f), Mamdc2, ${ }^{35} \mathrm{Mecom}_{1}{ }^{36} \mathrm{Zmat}_{4}{ }^{37} \mathrm{Dab2}^{38}$ Gpx3, $^{39}$ Ptprg, $^{40} \mathrm{Cds}^{41}$ or Spred $2^{42}$ (Supplementary Figure $9 \mathrm{~g}$ ). In addition, Ptpn6, ${ }^{43}$ Kank $1,^{44}{\text { Lrp } 1 b,{ }^{45} \text { Lrig } 3,^{46} \text { Nkd1, }}^{47}$ Crabp2, ${ }^{48}$ lgfbp $3^{49}$ and $C b x 7^{50}$ have been implicated in glioblastoma progression, confirming that invasiveness of glioblastoma and proliferation of RG progenitors use common molecules and signaling pathways. ${ }^{24}$

The most enriched terms in gene ontology for cellular component pointed to cilia, proteinaceous ECM (extracellular matrix) and intrinsic component of plasma membrane (Supplementary Table 3, Supplementary Figure 9h), suggesting that Celsr 1 may be instrumental to the communication between aNPC and their environment. Indeed, many differentially expressed genes encode extracellular proteins (Sulf1, Metallothionein-3, (Supplementary Figure 9i), Mmp2, Adamts2, Adamts18 (Supplementary Figure 9j), Galnt10 and Galnt12), membranebound proteins (Ptpn6, Ptprt, Sgms2, Tmsb4x (Supplementary Figure 9k) and Mamdc2 (Supplementary Figure 9l), ECM components (Tnc and Col1a2), or growth factor-binding proteins (Igfbp3 and lgfbp5). All these molecules can promote and regulate interactions between cell surface receptors, ligands and ECM.

Finally, it is worth mentioning that $10 \%(26 / 276)$ of misregulated genes are associated with ASD (Supplementary Table 4), and 2.5\% (7/276) with ADHD (Supplementary Table 5).

Celsr1 is required in aNPC endfeet to mediate RA signaling

The phenotype and transcriptional landscape of $\mathrm{Celsr}^{-1-}$ mutant aNPC indicate that they fail to perceive critical neurogenic signals. To examine the relationship between the loss of Celsr1 and the cortical phenotype, we studied the distribution of Celsr 1 protein in the embryonic mouse telencephalon and found that, prior to the onset of neurogenesis, Celsr 1 was confined to the apical junctions of NSC (Figures 3a-c). From e12.5 onwards, Celsr1 accumulated progressively in basal processes and endfeet of RG progenitors (Figures $3 \mathrm{~d}-\mathrm{i}$ ), as was shown in the brainstem and spinal cord. ${ }^{11,51}$ Because Celsr1 is a putative adhesion protein, we investigated the attachment of $\mathrm{RG}$ processes to the pia in Celsr1 ${ }^{-1-}$ mice. Immunohistochemistry with antibodies to the intermediate filament-associated protein Nestin showed that mutant aNPC were correctly oriented (Figures $3 \mathbf{j}, \mathrm{m}$ ) and reached the basal lamina (Figures 3k, n). Furthermore, we did not observe discontinuities in the basal lamina or neuronal heterotopia in meningeal spaces (Figures $3 \mathrm{l}, \mathrm{o}$ ). However, close scrutiny of the
aNPC basal compartment after electroporation of a Gfp encoding plasmid revealed that the number of basal processes was dramatically reduced in Celsr1 ${ }^{-/-}$mice (Figures $\left.3 p-r\right)$. Hence, Celsr1 redistributes to basal processes of aNPC at the onset of neurogenesis, and its deficiency affects their complexity. As mutant aNPC endfeet were drastically affected, we considered signals emanating from meninges, which were previously proposed to regulate brain development through secreted molecules. ${ }^{52,53}$ Chief among meningeal signals is RA, which is believed to trigger the switch from proliferative to neurogenic divisions at the onset of neurogenesis. ${ }^{52}$ Meningeal cells, the main source of RA in the developing cortex, appear progressively around the telencephalon in a lateral to dorsal gradient between e12.5 and e14.5, ${ }^{52}$ which correlates perfectly with the defect in BP production seen in Celsr1 ${ }^{-1-}$ cortex (Figure $1 \mathrm{~m}$, Supplementary Figure $3 n$ ). Furthermore, we found that Crabp2, a cytosol-tonuclear shuttling protein that facilitates the binding of RA to its cognate nuclear receptor, was concentrated in RG endfeet (Figures $4 a$, b) where it could mediate RA uptake and its relocation to the nucleus. In agreement with this hypothesis, the expression of $\mathrm{Crabp}^{48}$ as well as other RA target genes involved in neural differentiation such as $T n c^{24,54}$ and lgfbp $5^{55,56}$ was misregulated in Celsr $1^{-1-}$ mice (Supplementary Table 1, Figures $4 c, d$ ).

To test further whether RA is involved in the altered neurogenesis observed in mutant mice, we subjected $\mathrm{Celsr}^{-/-}$embryos to RA supplementation in utero between e11.5 and e14.5. This treatment restored the expression of Thc and Igfbp5 (Figures $4 \mathrm{e}, \mathrm{f}$ ). It also rescued the number of Tbr2-positive BP cells (Figures $4 \mathrm{~g}-\mathrm{k}, \mathrm{Tbr}^{+}$ cells in VZ/SVZ at e14.5, wild type $=458.8 \pm 13.8$, Celsr ${ }^{-1-}$ $=360.9 \pm 8.6, n=4, P<0.001$, two-way ANOVA; wild type+RA= $416.8 \pm 17.6, \mathrm{Celsr}^{-/-}+\mathrm{RA}=448.3 \pm 21.9, n=4, P>0.05$, two-way ANOVA); and the length of the VZ (Figures 4l-p, wild type $=0.57$ \pm 0.005 , Celsr $1^{-/-}=0.70 \pm 0.011, n=4, P<0.001$, two-way ANOVA; wild type+RA $=0.54 \pm 0.008, \quad$ Celsr $1^{-/-}+\mathrm{RA}=0.55 \pm 0.010, \quad n=4$, $P>0.05$, two-way ANOVA). Long-term RA supplementation (from e11.5 to e17.5) had profound consequences on the mature brain, and on behavior of adult mice (Figure 5). The treatment rescued the number of cortical neurons (number of $\mathrm{Cux}^{+}$cells: wild type$\mathrm{RA}=100 \%$, wild type+RA $=100.2 \%$, Celsr ${ }^{-1-}-\mathrm{RA}=85.1 \%, \mathrm{Celsr} 1^{-/-}$ $+\mathrm{RA}=100.6 \%, n=5, P>0.05$, Figure $5 \mathrm{a} ;$ ), and the hyperactivity and hiding behaviors (distance covered in open field: controls$\mathrm{RA}=9045 \pm 708.4 \mathrm{~cm}$, Celsr $1^{\text {Emx1cKO}}-\mathrm{RA}=13279 \pm 1175 \mathrm{~cm}$, controls $+\mathrm{RA}=8994 \pm 678.9 \mathrm{~cm}, \quad$ Celsr $1^{\text {Emx } 1 c K O}+\mathrm{RA}=7942 \pm 1493 \mathrm{~cm}, \quad n=9$, $P>0.05$ for RA treatment, one-way ANOVA, Figure 5b; time spent in exposed areas in open field: controls-RA $=195.7 \pm 26.3 \mathrm{~cm}$, Celsr1 ${ }^{\mathrm{Em} \times 1 \mathrm{cKO}}-\mathrm{RA}=320.5 \pm 37.8 \mathrm{~cm}$, controls $+R A=204 \pm 21.1 \mathrm{~cm}$, Celsr1 ${ }^{\mathrm{Em} \times 1 \mathrm{cKO}}+\mathrm{RA}=215.5 \pm 64.9 \mathrm{~cm}, n=9, P>0.05$ for RA treatment, one-way ANOVA, Figure $5 c$; time spent in open area in elevated plus maze: controls-RA $=1193 \pm 61.1 \mathrm{~cm}$, Celsr1 ${ }^{\text {Emx1cKO }}-\mathrm{RA}=1625 \pm$ $176.8 \mathrm{~cm}$, controls+RA $=1381 \pm 85.6 \mathrm{~cm}$, Celsr1 $^{\text {Emx } 1 c K O}+\mathrm{RA}=1279 \pm$ 136.2, $n=9, P>0.05$ for RA treatment, one-way ANOVA, Figure $5 \mathrm{~d}$ ), but it did not restore the learning abilities of the mutant males (time spent to find the platform after 3 days, controls-RA $=8.9 \pm$ $1.9 \mathrm{~s}$, Celsr1 ${ }^{\text {Emx1cKO }}-\mathrm{RA}=19.2 \pm 4.2 \mathrm{~s}$, controls $+R A=10.3 \pm 2.1 \mathrm{~s}$, Celsr ${ }^{E m \times 1 C K O}+\mathrm{RA}=19.8 \pm 5.2 \mathrm{~s}, n=9, P<0.05$ for day $1-3$, two-way ANOVA, Figure 5e). Long-term repetitive treatment with RA also rescued social interaction defects in Celsr $1^{\text {EmxicKO }}$ females (time spent in empty chamber Celsr1 ${ }^{\text {Emx1CKO}}-\mathrm{RA}=235.8 \pm 37.8 \mathrm{~s}$, with stranger $=257.1 \pm 44.5 \mathrm{~s}, \quad P>0.05, \quad$ Celsr $1^{E m \times 1 C K O}+$ RA in empty chamber $=96 \pm 37 \mathrm{~s}$, with stranger $=339 \pm 37 \mathrm{~s}, P<0.001, n=9$ animals per genotype, Student's $t$-test; Figure $5 f$ ). These results support a link between RA and the Celsri ${ }^{--}$phenotype.

\section{DISCUSSION}

The control of neurogenesis during embryonic development is crucial to regulate the number, diversity and position of neurons, and to normalize cortical size and architecture. At the onset of 
neurogenesis, aNPC integrate intrinsic and extrinsic signals that determine their fate choices. Here, we report that Celsr1, which localizes to the basal compartment of aNPC, ${ }^{51}$ contributes to such signals and regulates the type of division of progenitors. We propose that the basal compartment of aNPC interprets signals secreted from the meninges, such as that of RA, and thereby regulates expression of genes involved in the neurogenic switch.

Celsr1 mutant mice exhibit errors in neural progenitor fate decision that lead to a reduced number of cortical neurons, abnormal brain architecture (that is, thicker VZ/SVZ, and thinner upper layers of the neocortex), microcephaly and behavioral impairment. Celsr1 ${ }^{E m \times 1 C K O}$ mice are hyperactive and display abnormal exploratory behavior, spending more time than controls in exposed regions, and in unprotected arms of the elevated plus maze. The fact that mutant mice explore uncomfortable, risky, or threatening environments could be linked to anxiety-related responses or reflect a diminished attention to their environment, a conclusion supported by their reduced spacial learning abilities. In addition to the increased locomotor and reduced anxiety and/or attention in males, Celsr1 ${ }^{\text {Emx1CKO }}$ females spend significantly less time than controls interacting with a stranger mouse, a sign of social withdrawal. This combination of phenotypes is evocative of neurodevelopmental human disorders where: (i) ASD and ADHD co-occur with high frequency (up to $50 \%$ of children with ADHD meet criteria for ASD, and up to $80 \%$ of ASD children meet criteria for $A D H D ;{ }^{20}$ and (ii) Brains of patients with both ASD and hyperactivity displayed thickening of the VZ/SVZ and altered neurogenesis, ${ }^{57}$ in addition to microcephaly. ${ }^{58,59}$ In humans, neural tube closure defects and fetal lethality may have prevented the identification of causative links between CELSR1 and neurodevelopmental disorders in large cohorts. Nevertheless, CELSR1 mutations have been associated with autism, hyperactivity, delayed speech and intellectual disability (https://decipher. sanger.ac.uk/). ${ }^{60}$ Further studies using appropriately designed genome editing strategies and brain organoids should help assess the role of CELSR1 in human cortical development.

Mechanistically, we find that the Celsr1 protein is confined to apical junctions in NSC but distributes to the basal compartment in aNPC, and this localization is essential to shape the basal processes. Accumulation of proteins that regulate proliferation versus differentiation of neural progenitors in specific cell compartments and especially in aNPC endfeet has been reported. For instance, Cyclin D2, a crucial cell cycle regulator, accumulates in aNPC endfeet and, among cells that inherit basal processes after division, may promote re-entry into the cell cycle. ${ }^{61}$ Likewise, the Fragile $X$ mental retardation protein FMRP involved in the transition from aNPC to BP is also distributed in aNPC basal processes, ${ }^{62}$ where it controls transport and localization of kinesin Kif26a. ${ }^{63}$ Accumulation of the Celsr1 protein in aNPC endfeet may promote the branching and/or stabilization of the basal compartment of aNPC. Both processes require a coordinated reorganization of the cytoskeleton and involve actin and microtubules dynamics, a typical feature of PCP signaling. ${ }^{64}$ Celsr 1 is a sevenpass transmembrane protein of the adhesion $G$ protein-coupled receptor family with an ectodomain containing cadherin repeats, EGF, laminin and hormone receptor motifs, thus making it a good candidate to bridge the ECM and the cytoskeleton. Such an interaction is instrumental to aNPC morphogenesis and communication with meninges since the simplified shape of basal processes in Celsr1-deficient mice, correlates with alterations in gene expression, and with a defective neurogenic switch. Of note, the Celsr1 paralog Celsr3 is required at later embryonic stages for the gliogenic switch. ${ }^{65}$

The meninges are a source of developmental cues. The pia produces the chemoattractant $\mathrm{Cxcl} 12$ (Sdf1), which regulates the positioning of cortical interneurons and Cajal-Retzius cells. ${ }^{53}$ The dura is involved in skull development by producing TGF $\beta$ and FGF2 to induce bone formation. ${ }^{66,67}$ RA derived from meninges may play a role in the neurogenic induction during corticogenesis, ${ }^{52}$ even though this is debated. ${ }^{68}$ Our RNA-Seq data revealed that receptors and binding proteins involved in RA signaling (for example, Rara, Rar $\beta$, Rxra, Rxr $\beta$, Nr2f1, Crabp2, Ppard and Fabp5) are expressed in aNPC. Furthermore, removing RA-producing meninges by Foxc1 inactivation produces phenotypic features rather similar to those in $\mathrm{Celsr}^{-1-}$ mice (this study), and in RARa/y double knockout, ${ }^{69}$ namely an increased number of self-renewing divisions of aNPC with lateral expansion of the VZ. In addition, neurogenesis defects found in Celsri ${ }^{-/}$and Foxc $^{-/-}$mutants are both rescued by RA treatment. RA is a strong morphogen whose activity must be tightly regulated. Restricting its production to the meninges and its uptake by Crabp2, a shuttle protein which accumulates in aNPC endfeet, may provide an efficient way to deliver the appropriate amount of RA to the distant nucleus.

Transcriptional dysregulations found in Celsr1 ${ }^{-1}$ point to common pathways and mechanisms by which Celsr1, through the basal processes of aNPC, controls the switch from self-renewal to differentiation. Many genes and proteins that are differentially expressed in Celsr1 mutant aNPC modulate growth factor signaling at the membrane or via extracellular space. Tyrosine phosphatases (Ptpn6, Ptprt, Ptprg) which blocks the activation of tyrosine kinase receptors with known proliferation inducing activity, such as Egfr $^{70}$ or Pdgfrb, are reduced. Likewise, Sulf1, which decreases receptor affinity to ligands by modifying sulfation of their co-receptor heparin sulfate proteoglycans, ${ }^{71}$ is diminished. At the plasma membrane level, Lrig3, Myof and Spred2 (through receptor degradation and through interaction with $\mathrm{PI3K}$ ) also negatively regulate growth factors (FGF or EGF) signaling. ${ }^{72}$

\section{CONFLICT OF INTEREST}

The authors declare no conflict of interest.

\section{ACKNOWLEDGMENTS}

We thank Dr Xavier Morin for providing the pcx-Gfp plasmid, Catherine Lombard for her help with the UCL-IREC FACS platform and Valérie Bonte, R El Kaddouri, I Lambermont and E Paitre for technical support. This study made use of data generated by the DECIPHER community. A full list of centers who contributed to the generation of the data is available from http://decipher.sanger.ac.uk and via email from decipher@sanger.ac.uk. Funding for the project was provided by the Wellcome Trust. This work was supported by the following grants: FNRS PDR T0002.13, FNRS PDR T00075.15, Interuniversity Poles of Attraction (SSTC, PAI p6/20 and PAl7/20), Fondation Médicale Reine Elisabeth and Fondation JED-Belgique. FT is a Research Director of the Belgian Fund for Scientific Research (FNRS).

\section{REFERENCES}

1 Florio M, Huttner WB. Neural progenitors, neurogenesis and the evolution of the neocortex. Development 2014; 141: 2182-2194.

2 Noctor SC, Martinez-Cerdeno V, Kriegstein AR. Contribution of intermediate progenitor cells to cortical histogenesis. Arch Neurol 2007; 64: 639-642.

3 Fernandez V, Llinares-Benadero C, Borrell V. Cerebral cortex expansion and folding: what have we learned? EMBO J 2016; 35: 1021-1044.

4 Wang Y, Nathans J. Tissue/planar cell polarity in vertebrates: new insights and new questions. Development 2007; 134: 647-658.

5 Tissir F, Goffinet AM. Shaping the nervous system: role of the core planar cell polarity genes. Nat Rev Neurosci 2013; 14: 525-535.

6 Curtin JA, Quint E, Tsipouri V, Arkell RM, Cattanach B, Copp AJ et al. Mutation of Celsr1 disrupts planar polarity of inner ear hair cells and causes severe neural tube defects in the mouse. Curr Biol 2003; 13: 1129-1133.

7 Ravni A, Qu Y, Goffinet AM, Tissir F. Planar cell polarity cadherin Celsr1 regulates skin hair patterning in the mouse. J Invest Dermatol 2009; 129: 2507-2509.

8 Boutin C, Labedan P, Dimidschstein J, Richard F, Cremer H, Andre P et al. A dual role for planar cell polarity genes in ciliated cells. Proc Natl Acad Sci USA 2014; 111: E3129-E3138.

9 Shi D, Komatsu K, Hirao M, Toyooka Y, Koyama H, Tissir F et al. Celsr1 is required for the generation of polarity at multiple levels of the mouse oviduct. Development 2014; 141: 4558-4568. 
10 Tatin F, Taddei A, Weston A, Fuchs E, Devenport D, Tissir F et al. Planar cell polarity protein Celsr1 regulates endothelial adherens junctions and directed cell rearrangements during valve morphogenesis. Dev Cell 2013; 26: 31-44.

11 Qu Y, Glasco DM, Zhou L, Sawant A, Ravni A, Fritzsch B et al. Atypical cadherins Celsr1-3 differentially regulate migration of facial branchiomotor neurons in mice. J Neurosci 2010; 30: 9392-9401.

12 Robinson A, Escuin S, Doudney K, Vekemans M, Stevenson RE, Greene ND et al. Mutations in the planar cell polarity genes CELSR1 and SCRIB are associated with the severe neural tube defect craniorachischisis. Hum Mutat 2012; 33: 440-447.

13 Boutin C, Goffinet AM, Tissir F. Celsr1-3 cadherins in PCP and brain development. Curr Top Dev Biol 2012; 101: 161-183.

14 Miller JA, Ding SL, Sunkin SM, Smith KA, Ng L, Szafer A et al. Transcriptional landscape of the prenatal human brain. Nature 2014; 508: 199-206.

15 Furutachi S, Miya H, Watanabe T, Kawai H, Yamasaki N, Harada Y et al. Slowly dividing neural progenitors are an embryonic origin of adult neural stem cells. Nat Neurosci 2015; 18: 657-665.

16 Mirzadeh Z, Merkle FT, Soriano-Navarro M, Garcia-Verdugo JM, Alvarez-Buylla A. Neural stem cells confer unique pinwheel architecture to the ventricular surface in neurogenic regions of the adult brain. Cell Stem Cell 2008; 3: 265-278.

17 Russell VA. Neurobiology of animal models of attention-deficit hyperactivity disorder. J Neurosci Methods 2007; 161: 185-198.

18 Moy SS, Nadler JJ, Young NB, Nonneman RJ, Grossman AW, Murphy DL et al. Social approach in genetically engineered mouse lines relevant to autism. Genes Brain Behav 2009; 8: 129-142.

19 Silverman JL, Yang M, Lord C, Crawley JN. Behavioural phenotyping assays for mouse models of autism. Nat Revi Neuroscience. 2010; 11: 490-502.

20 Rommelse NN, Franke B, Geurts HM, Hartman CA, Buitelaar JK. Shared heritability of attention-deficit/hyperactivity disorder and autism spectrum disorder. Eur Child Adolesc Psychiatry 2010; 19: 281-295.

21 Wirsching HG, Kretz O, Morosan-Puopolo G, Chernogorova P, Theiss C, BrandSaberi B. Thymosin beta4 induces folding of the developing optic tectum in the chicken (Gallus domesticus). J Compar Neurol 2012; 520: 1650-1662.

22 Yang S, Cui J, Yang Y, Liu Z, Yan H, Tang C et al. Over-expressed RPL34 promotes malignant proliferation of non-small cell lung cancer cells. Gene 2016; 576: 421-428.

23 Ueda T, Nagamachi A, Takubo K, Yamasaki N, Matsui H, Kanai A et al. Fbxl10 overexpression in murine hematopoietic stem cells induces leukemia involving metabolic activation and upregulation of Nsg2. Blood 2015; 125: 3437-3446.

24 Pollen AA, Nowakowski TJ, Chen J, Retallack H, Sandoval-Espinosa C, Nicholas CR et al. Molecular identity of human outer radial glia during cortical development. Cell 2015; 163: 55-67.

25 You J, Fang N, Gu J, Zhang Y, Li X, Zu L et al. Noncoding RNA small nucleolar RNA host gene 1 promote cell proliferation in nonsmall cell lung cancer. Indian $J$ Cancer 2014; 51: e99-e102.

26 Noll JE, Vandyke K, Hewett DR, Mrozik KM, Bala RJ, Williams SA et al. PTTG1 expression is associated with hyperproliferative disease and poor prognosis in multiple myeloma. J Hematol Oncol 2015; 8: 106.

27 Vied CM, Freudenberg F, Wang Y, Raposo AA, Feng D, Nowakowski RS. A multi-resource data integration approach: identification of candidate genes regulating cell proliferation during neocortical development. Fronti Neurosci 2014; 8: 257.

28 Liu CT, Zhu ST, Li P, Wang YJ, Zhang H, Zhang ST. SULF1 inhibits proliferation and invasion of esophageal squamous cell carcinoma cells by decreasing heparinbinding growth factor signaling. Digest Dis Sci 2013; 58: 1256-1263.

29 Liang W, Guan H, He X, Ke W, Xu L, Liu L et al. Down-regulation of SOSTDC1 promotes thyroid cancer cell proliferation via regulating cyclin A2 and cyclin E2. Oncotarget 2015; 6: 31780-31791.

30 Park SJ, Jang HR, Kim M, Kim JH, Kwon OH, Park JL et al. Epigenetic alteration of CCDC67 and its tumor suppressor function in gastric cancer. Carcinogenesis 2012; 33: 1494-1501.

31 Scott A, Wang Z. Tumour suppressor function of protein tyrosine phosphatase receptor-T. Biosci Rep 2011; 31: 303-307.

32 Wang J, Ding N, Li Y, Cheng H, Wang D, Yang Q et al. Insulin-like growth factor binding protein 5 (IGFBP5) functions as a tumor suppressor in human melanoma cells. Oncotarget 2015; 6: 20636-20649.

33 Vanharanta S, Marney CB, Shu W, Valiente M, Zou Y, Mele A et al. Loss of the multifunctional RNA-binding protein RBM47 as a source of selectable metastatic traits in breast cancer. elife 2014; 3. doi: 10.7554/eLife.02734.

34 Barrett CW, Reddy VK, Short SP, Motley AK, Lintel MK, Bradley AM et al. Selenoprotein $\mathrm{P}$ influences colitis-induced tumorigenesis by mediating stemness and oxidative damage. J Clin Invest 2015; 125: 2646-2660.

35 Darda L, Hakami F, Morgan R, Murdoch C, Lambert DW, Hunter KD. The role of HOXB9 and miR-196a in head and neck squamous cell carcinoma. PloS ONE 2015; 10: e0122285.
36 Hou A, Zhao L, Zhao F, Wang W, Niu J, Li B et al. Expression of MECOM is associated with unfavorable prognosis in glioblastoma multiforme. OncoTargets Ther 2016; 9: 315-320.

37 Wan J, Gao Y, Zhao X, Wu Q, Fu X, Shao Y et al. The association between the copynumber variations of ZMAT4 and hematological malignancy. Hematology 2011; 16: $20-23$.

38 Zhang Z, Chen Y, Xie X, Tang J. The expression of disabled-2 is common reduced in meningiomas. Neurol India 2014; 62: 57-61.

39 Barrett CW, Ning W, Chen X, Smith JJ, Washington MK, Hill KE et al. Tumor suppressor function of the plasma glutathione peroxidase gpx3 in colitisassociated carcinoma. Cancer Res 2013; 73: 1245-1255.

40 Cheung AK, Ip JC, Chu AC, Cheng Y, Leong MM, Ko JM et al. PTPRG suppresses tumor growth and invasion via inhibition of Akt signaling in nasopharyngeal carcinoma. Oncotarget 2015; 6: 13434-13447.

41 McGowan $\mathrm{CH}$. Checking in on Cds1 (Chk2): a checkpoint kinase and tumor suppressor. BioEssays 2002; 24: 502-511.

42 Kachroo N, Valencia T, Warren AY, Gnanapragasam VJ. Evidence for downregulation of the negative regulator SPRED2 in clinical prostate cancer. $\mathrm{Br} J$ Cancer 2013; 108: 597-601.

43 Sooman L, Ekman S, Tsakonas G, Jaiswal A, Navani S, Edqvist PH et al. PTPN6 expression is epigenetically regulated and influences survival and response to chemotherapy in high-grade gliomas. Tumour Biol 2014; 35: 4479-4488.

44 Guo X, Fan W, Bian X, Ma D. Upregulation of the Kank1 gene-induced brain glioma apoptosis and blockade of the cell cycle in G0/G1 phase. Int J Oncol 2014 44: 797-804.

45 Tabouret $E$, Labussiere $M$, Alentorn A, Schmitt $Y$, Marie $Y$, Sanson M. LRP1B deletion is associated with poor outcome for glioblastoma patients. J Neurol Sci 2015; 358: 440-443.

46 Guo D, Yang H, Guo Y, Xiao Q, Mao F, Tan Y et al. LRIG3 modulates proliferation, apoptosis and invasion of glioblastoma cells as a potent tumor suppressor. $J$ Neurol Sci 2015; 350: 61-68.

47 Gotze S, Wolter M, Reifenberger G, Muller O, Sievers S. Frequent promoter hypermethylation of Wnt pathway inhibitor genes in malignant astrocytic gliomas. Int J Cancer 2010; 126: 2584-2593.

48 Campos B, Warta R, Chaisaingmongkol J, Geiselhart L, Popanda O, Hartmann C et al. Epigenetically mediated downregulation of the differentiation-promoting chaperon protein CRABP2 in astrocytic gliomas. Int J Cancer 2012; 131: 1963-1968.

49 Yang $\mathrm{CH}$, Yue J, Pfeffer SR, Fan M, Paulus E, Hosni-Ahmed A et al. MicroRNA-21 promotes glioblastoma tumorigenesis by down-regulating insulin-like growth factor-binding protein-3 (IGFBP3). J Biol Chem 2014; 289: 25079-25087.

50 Li G, Warden C, Zou Z, Neman J, Krueger JS, Jain A et al. Altered expression of polycomb group genes in glioblastoma multiforme. PloS ONE 2013; 8: e80970.

51 Formstone CJ, Moxon C, Murdoch J, Little P, Mason I. Basal enrichment within neuroepithelia suggests novel function(s) for Celsr1 protein. Mol Cell Neurosci 2010; 44: 210-222.

52 Siegenthaler JA, Ashique AM, Zarbalis K, Patterson KP, Hecht JH, Kane MA et al. Retinoic acid from the meninges regulates cortical neuron generation. Cell 2009; 139: $597-609$.

53 Borrell V, Marin O. Meninges control tangential migration of hem-derived Cajal-Retzius cells via CXCL12/CXCR4 signaling. Nat Neurosci 2006; 9: 1284-1293.

54 Alvarez-Dolado M, Gonzalez-Sancho JM, Navarro-Yubero C, Garcia-Fernandez LF, Munoz A. Retinoic acid and 1,25-dihydroxyvitamin D3 inhibit tenascin-C expression in rat glioma C6 cells. J Neurosci Res 1999; 58: 293-300.

55 Chang YS, Cho JY, Cho HA, Kim HJ, Chang J, Ahn CM et al. 9-cis retinoic acid induces insulin-like growth factor binding protein-3 through DR-8 retinoic acid responsive elements. Cancer Biol Ther 2006; 5: 586-592.

56 Dong Y, Canalis E. Insulin-like growth factor (IGF) I and retinoic acid induce the synthesis of IGF-binding protein 5 in rat osteoblastic cells. Endocrinology 1995; 136: 2000-2006.

57 Wegiel J, Kuchna I, Nowicki K, Imaki H, Wegiel J, Marchi E et al. The neuropathology of autism: defects of neurogenesis and neuronal migration, and dysplastic changes. Acta Neuropathol 2010; 119: 755-770.

58 Ben-Itzchak E, Ben-Shachar S, Zachor DA. Specific neurological phenotypes in autism spectrum disorders are associated with sex representation. Autism Res 2013; 6: 596-604.

59 Giedd JN, Blumenthal J, Molloy E, Castellanos FX. Brain imaging of attention deficit/hyperactivity disorder. Ann N Y Acad Sci 2001; 931: 33-49.

60 Firth HV, Richards SM, Bevan AP, Clayton S, Corpas M, Rajan D et al. DECIPHER: database of chromosomal imbalance and phenotype in humans using ensembl resources. Am J Hum Genet 2009; 84: 524-533.

61 Tsunekawa Y, Britto JM, Takahashi M, Polleux F, Tan SS, Osumi N. Cyclin D2 in the basal process of neural progenitors is linked to non-equivalent cell fates. $E M B O \mathrm{~J}$ 2012; 31: 1879-1892.

62 Saffary $R$, Xie Z. FMRP regulates the transition from radial glial cells to intermediate progenitor cells during neocortical development. J Neurosci 2011; 31: 1427-1439. 
63 Pilaz LJ, Lennox AL, Rouanet JP, Silver DL. Dynamic mRNA transport and local translation in radial glial progenitors of the developing brain. Curr Biol 2016; 26: 3383-3392.

64 Adler PN. The frizzled/stan pathway and planar cell polarity in the Drosophila wing. Curr Top Dev Biol 2012; 101: 1-31.

65 Wang W, Jossin Y, Chai G, Lien WH, Tissir F, Goffinet AM. Feedback regulation of apical progenitor fate by immature neurons through Wnt7-Celsr3-Fzd3 signalling. Nat Commun 2016; 7: 10936.

66 Ito Y, Yeo JY, Chytil A, Han J, Bringas P Jr., Nakajima A et al. Conditional inactivation of Tgfbr2 in cranial neural crest causes cleft palate and calvaria defects. Development 2003; 130: 5269-5280.

67 Mehrara BJ, Greenwald J, Chin GS, Dudziak M, Sagrioglu J, Steinbrech DS et al. Regional differentiation of rat cranial suture-derived dural cells is dependent on association with fusing and patent cranial sutures. Plastic Reconstruct Surg 1999; 104: 1003-1013.

68 Chatzi C, Cunningham TJ, Duester G. Investigation of retinoic acid function during embryonic brain development using retinaldehyde-rescued Rdh10 knockout mice. Dev Dynamics 2013; 242: 1056-1065.

69 Lohnes D, Mark M, Mendelsohn C, Dolle P, Dierich A, Gorry P et al. Function of the retinoic acid receptors (RARs) during development (I). Craniofacial and skeletal abnormalities in RAR double mutants. Development 1994; 120: 2723-2748.
70 Forbes K, Skinner L, Aplin JD, Westwood M. The tyrosine phosphatase SHP-1 negatively regulates cytotrophoblast proliferation in first-trimester human placenta by modulating EGFR activation. Cell Mol Life Sci 2012; 69: 4029-4040.

71 Lai J, Chien J, Staub J, Avula R, Greene EL, Matthews TA et al. Loss of HSulf-1 upregulates heparin-binding growth factor signaling in cancer. $J$ Biol Chem 2003; 278: 23107-23117.

72 Mardakheh FK, Yekezare M, Machesky LM, Heath JK. Spred2 interaction with the late endosomal protein NBR1 down-regulates fibroblast growth factor receptor signaling. J Cell Biol 2009; 187: 265-277.

(c) (i) $(-)$ This work is licensed under a Creative Commons AttributionNonCommercial-NoDerivs 4.0 International License. The images or other third party material in this article are included in the article's Creative Commons license, unless indicated otherwise in the credit line; if the material is not included under the Creative Commons license, users will need to obtain permission from the license holder to reproduce the material. To view a copy of this license, visit http:// creativecommons.org/licenses/by-nc-nd/4.0/

(c) The Author(s) 2018

Supplementary Information accompanies the paper on the Molecular Psychiatry website (http://www.nature.com/mp) 